\title{
Wavelet Analysis Statistical Data
}

\section{Mazurkin Peter Matveevich}

Department of Environmental Engineering, Volga State University of Technology, Yoshkar-Ola, Republic of Mari El, Russian Federation

\section{Email address:}

kaf_po@mail.ru

\section{To cite this article:}

Mazurkin Peter Matveevich. Wavelet Analysis Statistical Data. Advances in Sciences and Humanities. Vol. 1, No. 2, 2015, pp. 30-44. doi: 10.11648/j.ash.20150102.11

\begin{abstract}
Examples of modeling, identification of the amount of asymmetric wavelet signal behavior of natural objects: the pulse of the electrocardiogram of a healthy person; natural drying samples meadow grass; mutual influence of forest cover and tilled territory; Crisis dynamics of the ruble and default $1998 \mathrm{y}$;; volume of patenting and forecast innovations in Russia until $2020 \mathrm{y}$; dynamics of forest fires in the national park for the 1982-2011 y.; hour increments pulses alpha decay ${ }^{239} \mathrm{Pu}$ sample at the maximum of the solar eclipse; amplitude of gravitational waves from the orbital period of 10 pulsars in the model splashing Universe.
\end{abstract}

Keywords: Wavelet Signal, Generalized Model, Identification, Examples, Patterns

\section{Introduction}

Unlike deductive approach to wavelet analysis $[1,2,17]$ proceeding from the equations of classical mathematics inductive approach when statistical selection is primary is offered and concerning it the structure and values of parameters of the generalized wave function $[9,10,11,15,21$, 23 ] is identified.

Any phenomenon (time cut) or process (change in time) according to sound tabular statistical quantitative data (a numerical field) inductively can be identified the sum of asymmetric wavelet signals of a look

$$
\begin{gathered}
y=\sum_{i=1}^{m} y_{i}, \quad y_{i}=A_{i} \cos \left(\pi x / p_{i}-a_{8 i}\right), \\
A_{i}=a_{1 i} x^{a_{2 i}} \exp \left(-a_{3 i} x^{a_{4 i}}\right), \quad p_{i}=a_{5 i}+a_{6 i} x^{a_{7 i}},
\end{gathered}
$$

where $\mathrm{y}$ - indicator (dependent variable), i - number of the making statistical model (1), $\mathrm{m}$ - the number of members of model depending on achievement of the remains from (1) error of measurements, $\mathrm{x}$ - explanatory variable, $\mathrm{A}_{\mathrm{i}}$ amplitude (half) of fluctuation (ordinate), $\mathrm{p}_{\mathrm{i}}$ - half-cycle of fluctuation (abscissa), $a_{1} \ldots a_{8}$ - the parameters of model (1) determined in the program environment CurveExpert (URL: http://www.curveexpert.net/).

On a formula (1) with two fundamental physical constants e (Napier's number or number of time) and $\pi$ (Archimedes's number or number of space) the quantized wavelet signal is formed from within the studied phenomenon and/or process.

Further we will show some different examples of the wavelet analysis.

\section{Asymmetric Signals of the Electrocardiogram}

The purpose - receiving mathematical model of a signal of the electrocardiogram [13]. One period of an electrocardiographic signal without pathology in a reference system is set $\mathrm{U}(\mathrm{t})$, where: $\mathrm{t}$ - time measured in milliseconds (ms); $\mathrm{U}$ - heart tension in millivolts $(\mathrm{mV})$. The signal is given in figure 1 .

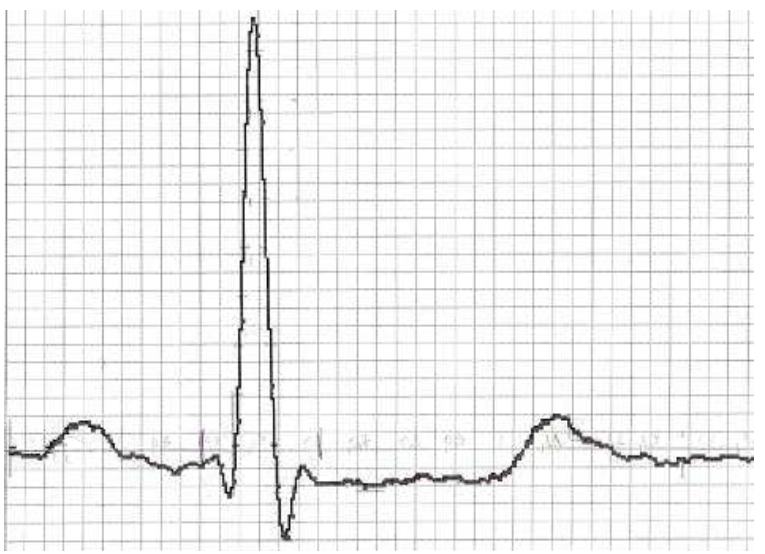

Figure 1. A grid for measurements of a signal of heart. 
In process of complication of a formula from the previous session of search more and more exact records of coefficients (model parameters) are accepted. Process comes to the end with the difficult nonlinear polynomial equation. The received equation will be mathematical model of this one signal of the electrocardiogram.

The schedule $U(t)$ of binomial model corresponding to the QRS complex of heart of the healthy person is given in figure 2 .

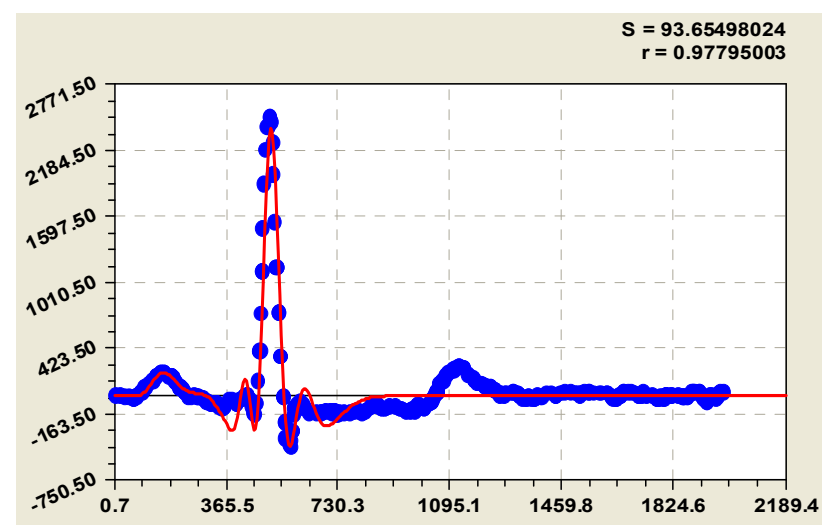

Figure 2. Work of an auricle and ventricle of heart.

On the remains from the model in figure 2 corresponding to a tooth of $\mathrm{T}$ of a signal of the electrocardiogram of heart of the healthy person it is shown in figure 3 .

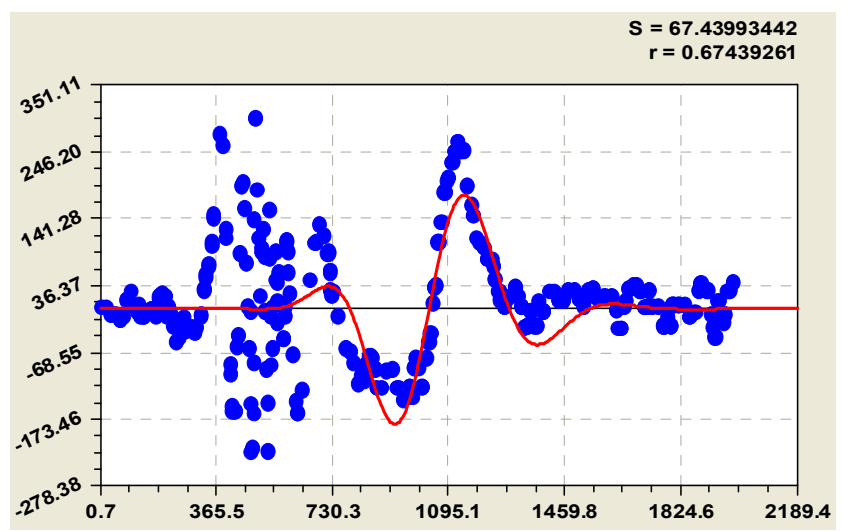

Figure 3. Work of an auricle after a heart ventricle.

From the fifth component on the thirty third new asymmetric signals are received. But their accessory to fluctuations of cardiac muscles the implicit. Apparently, schedules of tension of electric signals can belong and to other human organs.

Parameters of model (1) and coefficient of correlation are specified in table 1 .

Table 1. Parameters of mathematical model of the electrocardiogram of heart without pathology.

\begin{tabular}{|c|c|c|c|c|c|c|c|c|c|}
\hline \multirow{2}{*}{$\mathrm{i}$} & \multicolumn{4}{|c|}{ Amplitude of fluctuation, $\mathrm{mV}$} & \multicolumn{4}{|c|}{$\begin{array}{l}\text { Half-cycle and shift } \\
\text { of fluctuation, ms }\end{array}$} & \multirow{2}{*}{$\begin{array}{l}\text { Correl. } \\
\text { coef. }\end{array}$} \\
\hline & $a_{1 i}$ & $\mathrm{a}_{2 \mathrm{i}}$ & $\mathrm{a}_{3 \mathrm{i}}$ & $\mathrm{a}_{4 \mathrm{i}}$ & $\mathrm{a}_{5 \mathrm{i}}$ & $\mathrm{a}_{6 \mathrm{i}}$ & $\mathrm{a}_{7 \mathrm{i}}$ & $a_{8 i}$ & \\
\hline 1 & $2.59574 \mathrm{e}-028$ & 16.74766 & 0.078955 & 1.04811 & 0 & 0 & 0 & 0 & \\
\hline 2 & $1.42992 \mathrm{e}-149$ & 63.76683 & 0.013904 & 1.30529 & 10.59449 & 0.0022405 & 1.34410 & 3.18773 & 0.9780 \\
\hline 3 & $-3.40070 \mathrm{e}-033$ & 14.31631 & 0.000120 & 1.77400 & 21.15976 & 0.21683 & 0.87313 & 0.52152 & \\
\hline 4 & $-1.67937 \mathrm{e}-064$ & 25.57819 & 0.021603 & 1.01816 & 244.7042 & 0.0030608 & 0.98941 & 5.23804 & 0.6740 \\
\hline
\end{tabular}

The first three components give coefficient of correlation 0.9780 . Therefore the equation (1) quite sufficient to facilitate to the cardiologist diagnostics of heart according to the digital electrocardiogram.

The signal of the electrocardiogram is measured in 0.001 seconds to $2200 \mathrm{~ms}$. Processing of signals in seismic exploration demands a time scale also in 0.001 seconds to $2500 \mathrm{~ms}$ [1, page 29, fig. 1.1]. In neurodynamics the time scale in 1 second till 1000 seconds is applied [2, page 90, fig. 2.2a]. In different examples of measurements and the wavelet analysis other units of time are applied.

\section{Dynamics of Mass of Moisture During Natural Drying of Tests of a Grass}

In the course of natural drying of the cut-off elevated part of a grass there are, at least, two processes: first, dehydration yet not of dead cellular structures from action of heat of air; secondly, moisture deduction by the deadened cages before evaporation of free moisture. In this example a unit of time is 1 hour to $2000 \mathrm{~h} \mathrm{[16].}$
Dynamics of mass of test No. 1 during natural drying of the cut-off test of a grass to ready hay on a trial platform is characterized by the equation (1) in a look

$$
\begin{gathered}
\mathrm{m}_{\mathrm{t}}=\mathrm{m}_{\mathrm{t} 1}+\mathrm{m}_{\mathrm{t} 2}+\mathrm{m}_{\mathrm{t} 3}+\mathrm{m}_{\mathrm{t} 4} \\
\mathrm{~m}_{\mathrm{t} 1}=248.199, \mathrm{~m}_{\mathrm{t} 2}=656.388 \exp \left(-0.027137 \mathrm{t}^{0.97918}\right) \\
\mathrm{m}_{\mathrm{t} 3}=\mathrm{A}_{1} \cos \left(\pi \mathrm{t} / \mathrm{p}_{1}-0.23480\right) \\
\mathrm{A}_{1}=-26.05914 \exp (-0.0036376 \mathrm{t}) \\
\mathrm{p}_{1}=6.93112+0.00019461 \mathrm{t} \\
\mathrm{m}_{\mathrm{t} 4}=\mathrm{A}_{2} \cos \left(\pi \mathrm{t} / \mathrm{p}_{2}+2.38942\right) \\
\mathrm{A}_{2}=7.05798 \mathrm{t}^{0.55718} \exp (-0.029730 \mathrm{t}) \\
\mathrm{p}_{1}=19.31141+0.032157 \mathrm{t}
\end{gathered}
$$

In a formula (2) there are following symbols: $\mathrm{m}_{\mathrm{t}}$ - the mass of test of a grass in dynamics of natural drying, $\mathrm{g} / \mathrm{m} 2$, 
$\mathrm{m}_{\mathrm{t} 1}$ - mass of dry hay or grass of an air and dry state, $\mathrm{g} / \mathrm{m} 2$, $\mathrm{m}_{\mathrm{t} 2}$ - the mass of water in test of a grass in dynamics of its drying, $\mathrm{g} / \mathrm{m} 2, \mathrm{~m}_{\mathrm{t} 3}$ - oscillatory indignation of cages of the cut-off grass, $\mathrm{g} / \mathrm{m} 2, \mathrm{~m}_{\mathrm{t} 4}$ - oscillatory return of free water cages of a grass, $\mathrm{g} / \mathrm{m} 2$, $\mathrm{t}$ - time of natural drying from the moment of cutting of test of a grass, $\mathrm{h}, \mathrm{m}_{\mathrm{tB} 0}=656.388$ - the mass of initial moisture in grass test, $\mathrm{g} / \mathrm{m} 2, \mathrm{~A}_{1}$ - amplitude (half) of indignation of cages of test of a grass, $\mathrm{g} / \mathrm{m} 2, \mathrm{~A}_{2}$ amplitude (half) of indignation of the cages trying to reanimate circulation of moisture and to receive mineral substances, $\mathrm{g} / \mathrm{m} 2, \mathrm{p}_{1}$ - the period (half) of indignation on moisture loss, $h, p_{2}$ - the period (half) of indignation on recession of a metabolism, $h$.

The schedules constructed on a formula (2) are given in figure 4, and it has accurate physical interpretation of behavior of a grass after its cut.

The maximum relative error is equal $\left|\Delta_{\max }\right|=1.46 \%$. The increased waves are shown in figure 5 . During the first $500 \mathrm{~h}$ natural drying in test of a grass there is a sharp fluctuation of dynamic weight $\mathrm{m}_{\mathrm{t} 4}$.

From schedules it is visible that the dynamic component $\mathrm{m}_{\mathrm{t} 4}$ quickly dies away in limits till 200 o'clock drying, and less dynamic component $\mathrm{m}_{\mathrm{t} 3}$ proceeds.

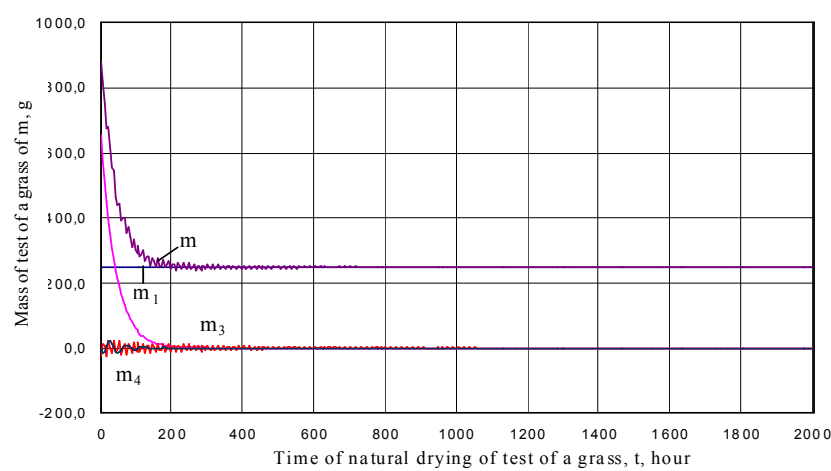

Figure 4. Dynamics of mass of a grass on a platform No. 1 .

From four components on all 18 models type (2) criteria for an ecological and landscape assessment of a meadow are received:

1) rational time $t_{p}$ of natural drying of the cut-off grass to ready hay, h;

2) optimum time $t_{o p t}$ of drying, $h$;

3) maximum time $t_{\max }$ of drying of a grass, $h$;

4) air and dry mass of test of a grass $m_{1}=m_{c}$ or hay, g/m2;

5) minimum mass of test $\mathrm{m}_{\phi \min }, \mathrm{g} / \mathrm{m} 2$;

6) the maximum mass of a grass $m_{t=0}$ after a cut, $g / m 2$;

7) the actual mass $m_{\phi 0}$ of test of the cut-off grass, $g / \mathrm{m} 2$;

8) coefficient of dynamism of mass $k_{c}$ of the dried grass from humidity of air, as the relation of the third member (2) to the first;
9) coefficient of dynamism $\mathrm{k}_{\text {вл }}$ of oscillatory return of moisture grass cages when drying;

10) the general coefficient of dynamism $\mathrm{k}$ as the relation of the third with the fourth to the sum of the first and second members;

11) wave coefficient $\mathrm{k}^{\text {сушки }}$ of dynamism of drying and moistening (the sum of the third and fourth components to the first);

12) humidity of test, \%: a) $\mathrm{W}_{t}$ in a statics (the second part to the first); b) $\mathrm{W}_{\mathrm{t}}^{\text {дин }}$ in dynamics (the sum of the second, third and fourth parts to the first).

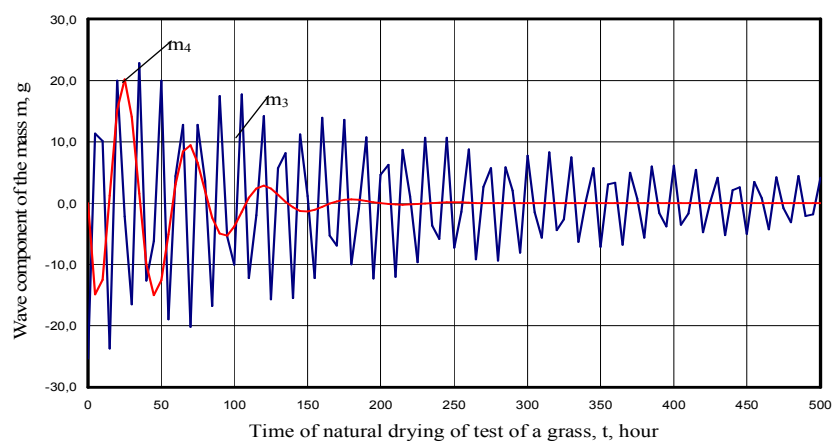

Figure 5. Wave components (2) to $500 \mathrm{~h}$.

Further we will show the analysis of the land registry of the Kirov region in time cut (year) on mutual influence of the wood (a biosphere kernel) and arable lands (an agriculture kernel).

\section{Influence of Plowing on Woodiness of the Territory}

The model of influence $\zeta$ of plowing $\xi$ on woodiness was executed in the program environment CurveExpert-1.38 [14].

On all 39 points (fig. 6a) the trend as the law of exponential death is received

$$
\xi=89.423 \exp \left(-0.020159 \varsigma^{1.03112}\right) .
$$

After identification (1) dependence with two waves was received (fig. 6b):

$$
\begin{gathered}
\xi=88.1519 \exp \left(-0.015018 \varsigma^{1.09609}\right)- \\
-\mathrm{A}_{1} \cos \left(\pi \varsigma / \mathrm{p}_{1}+3.73625\right)-\mathrm{A}_{2} \cos \left(\pi \varsigma / \mathrm{p}_{2}-2.93701\right) \\
\mathrm{A}_{1}=1.6271 \cdot 10^{-11} \varsigma^{11.66004} \exp \left(-0.37494 \varsigma^{1.03215}\right) \\
\mathrm{p}_{1}=0.98432-0.00022766 \varsigma^{1.29696} \\
\mathrm{~A}_{2}=1.9405 \cdot 10^{-6} \varsigma^{4.86423} \exp \left(-0.073799 \varsigma^{1.06910}\right) \\
\mathrm{p}_{2}=1.17786+2.5262 \cdot 10^{-5} \varsigma^{1.36585}
\end{gathered}
$$



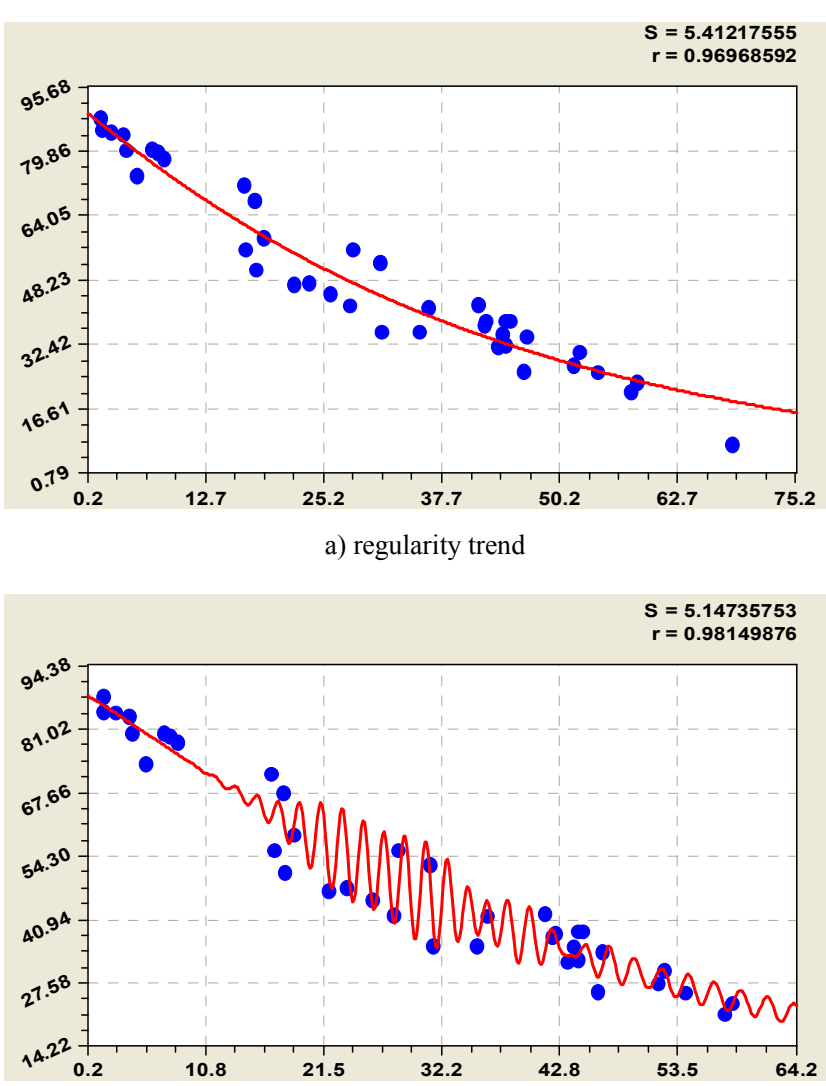

b) trend and accounting of two waves of a tremor

Figure 6. Change of woodiness of from plowing of the territory of rural regions of the Kirov region.

Both fluctuations have a negative sign, therefore indignations crisis. In figure $6 \mathrm{~b}$ three clusters of municipalities having different style of behavior are visible.

\section{Influence of Woodiness of on Plowed of the Territory}

And as woodiness of the territory influences on percentage of plowing? [14].

The trend received (fig. 7a) a formula

$$
\varsigma=71.0128 \exp \left(-0.00074784 \xi^{1,4148}\right) \text {. }
$$

Connectivity $\varsigma=\mathrm{f}(\xi)$ is better in comparison with structure $\xi=\mathrm{f}(\varsigma)$. Thus, at the heart of relationship with the earth nevertheless the ancient tradition of fire agriculture which nowadays and developments is in the heat of growth in the territory of the Amazon River remained. In the Kirov region this technology to the wood isn't applied.

After identification of a trend and two wavelets of crisis oscillatory indignation of rural regions of the Kirov region the look formula was received (fig. 7b)
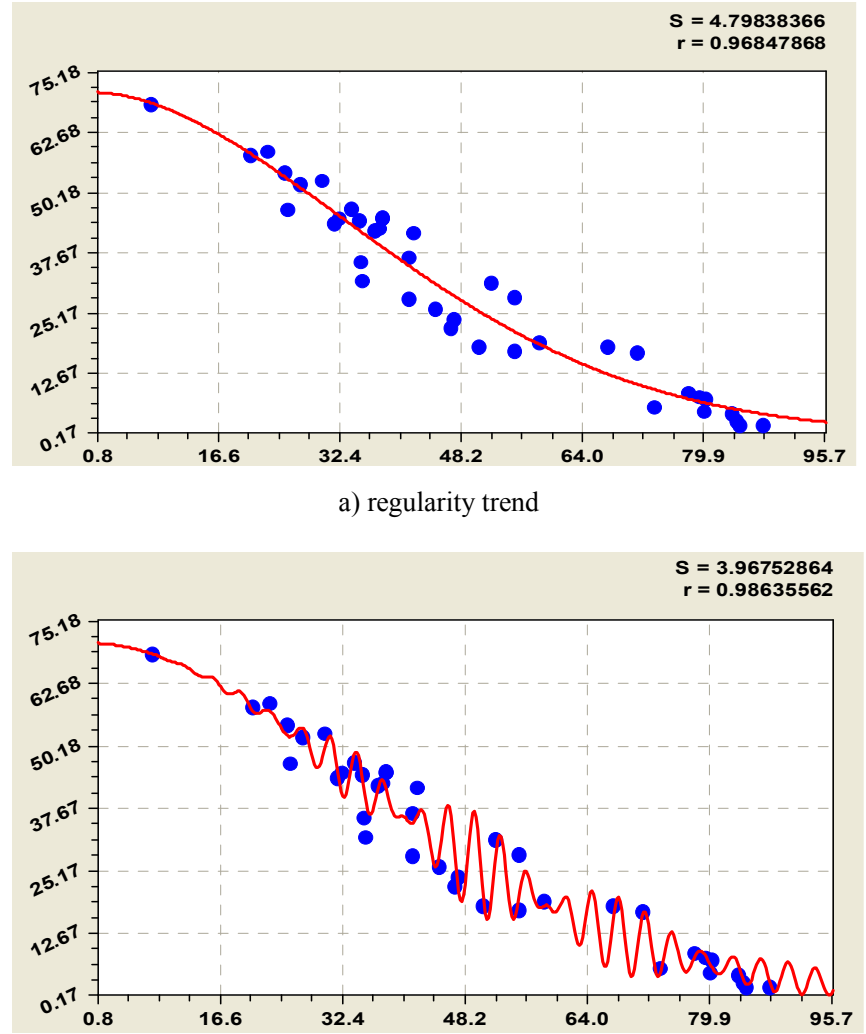

b) trend and accounting of two waves of a tremor

Figure 7. Changing plowing from woodiness of the territory of rural regions of the Kirov region.

$$
\begin{gathered}
\varsigma=70.6987 \exp \left(-0.00069398 \xi^{1.85728}\right)- \\
-\mathrm{A}_{1} \cos \left(\pi \xi / \mathrm{p}_{1}+1.92141\right)-\mathrm{A}_{2} \cos \left(\pi \xi / \mathrm{p}_{2}-3.46367\right), \\
\mathrm{A}_{1}=5.5756 \cdot 10^{-10} \xi^{7.15573} \exp \left(-0.025332 \xi^{1.35448}\right) \\
\mathrm{p}_{1}=1.48498+0.0024279 \xi^{0.70307} \\
\mathrm{~A}_{2}=1.8184 \cdot 10^{-5} \xi^{4.22294} \exp \left(-0.077257 \xi^{1.00723}\right) \\
\mathrm{p}_{2}=1.91267-0.00029107 \xi^{1.12624}
\end{gathered}
$$

In total six more wavelet functions from which four are adaptation indignations (a positive sign ahead of a component), and two - crisis fluctuations were found. Thus, the total of crisis indignations is also equal to four. In total in statistical model nine members are formed.

The first adaptation happened (fig. 8a) on a formula

$$
\begin{gathered}
\varsigma_{4}=\mathrm{A}_{3} \cos \left(\pi \xi / \mathrm{p}_{3}-2.35408\right) \\
\mathrm{A}_{3}=0.0010605 \xi^{3.43357} \exp \left(-0.10955 \xi^{1.01955}\right) \\
\mathrm{p}_{3}=1.67066+0.0092795 \xi^{1.00397}
\end{gathered}
$$

The second adaptation (fig. 8b) happened on dependence

$$
\varsigma_{5}=\mathrm{A}_{4} \cos \left(\pi \xi / \mathrm{p}_{4}+2.11013\right),
$$




$$
\begin{gathered}
\mathrm{A}_{4}=3.3093 \cdot 10^{-5} \xi^{4.28026} \exp \left(-0.06349 \xi^{1,8919}\right), \\
\mathrm{p}_{4}=1.29604+2.39925 \xi^{0.066338} .
\end{gathered}
$$

The adaptation of waves goes from left to right, reducing

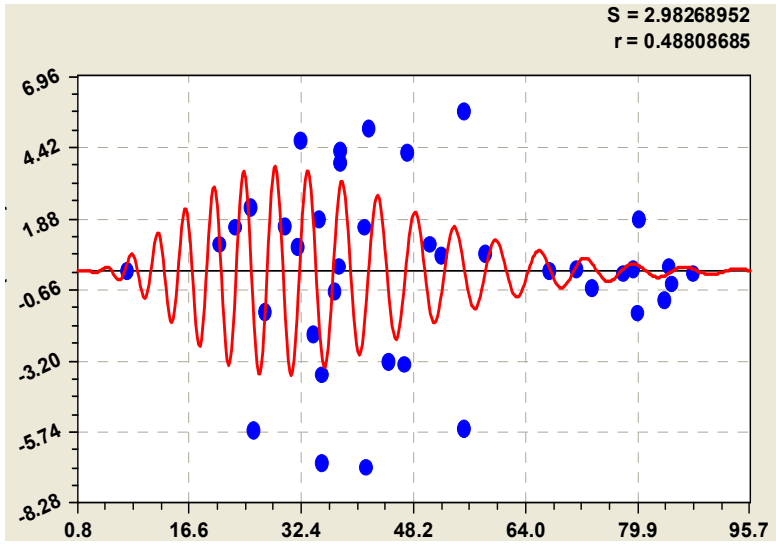

a) first adaptation of plowing

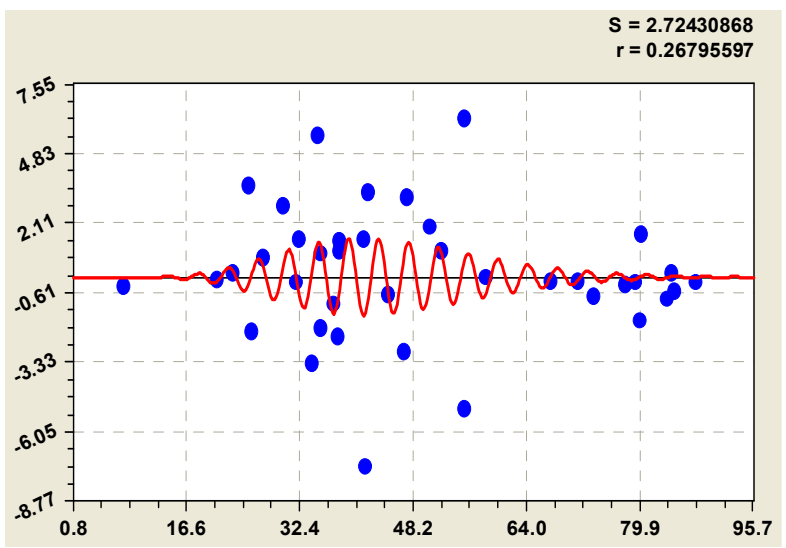

c) third adaptation of plowing

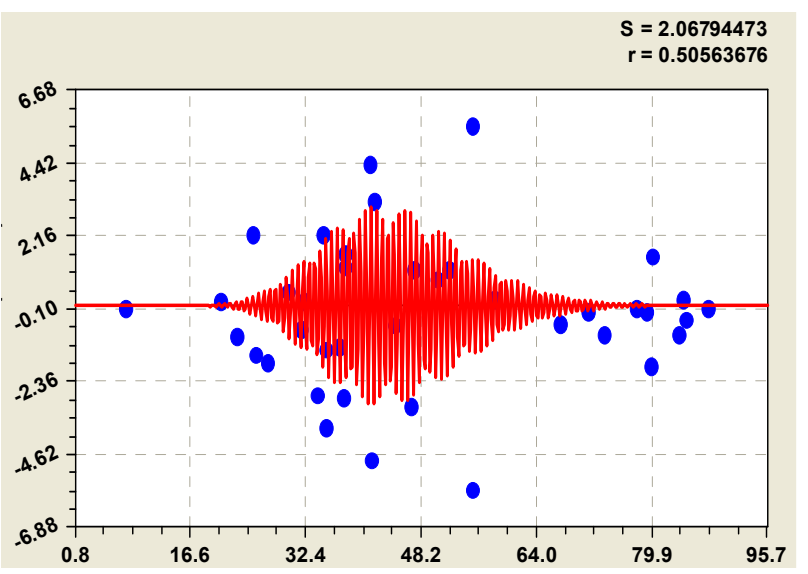

e) crisis on the seventh wave values of the remains of an indicator of plowing of the territory. Thus it is noticeable that rural areas with the high level of woodiness don't react to an indicator of plowing as in their territories the forest industry is developed.

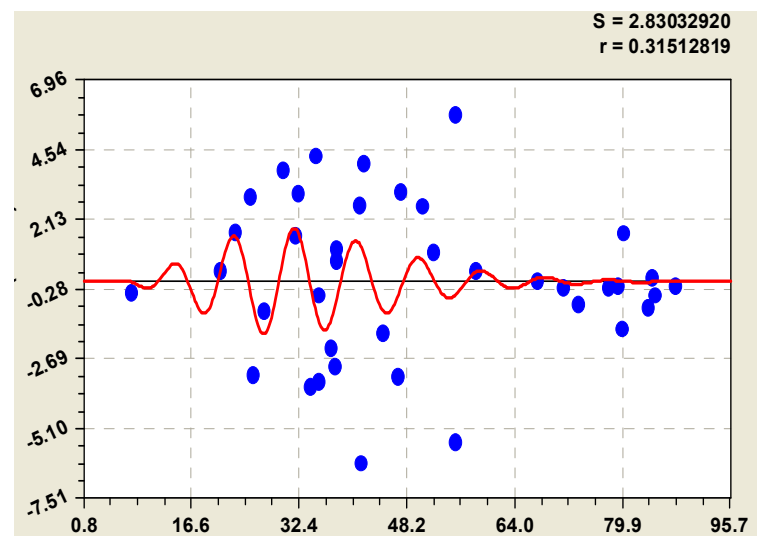

b) second adaptation of plowing

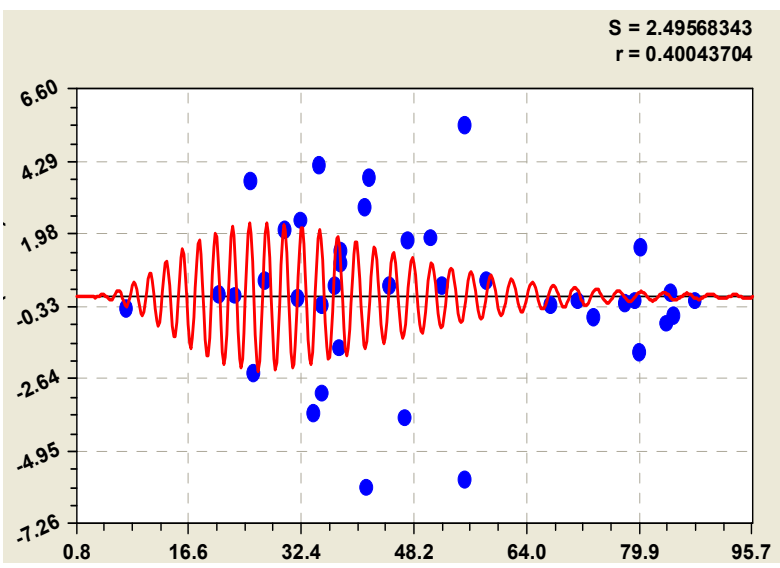

d) fourth wave of adaptation

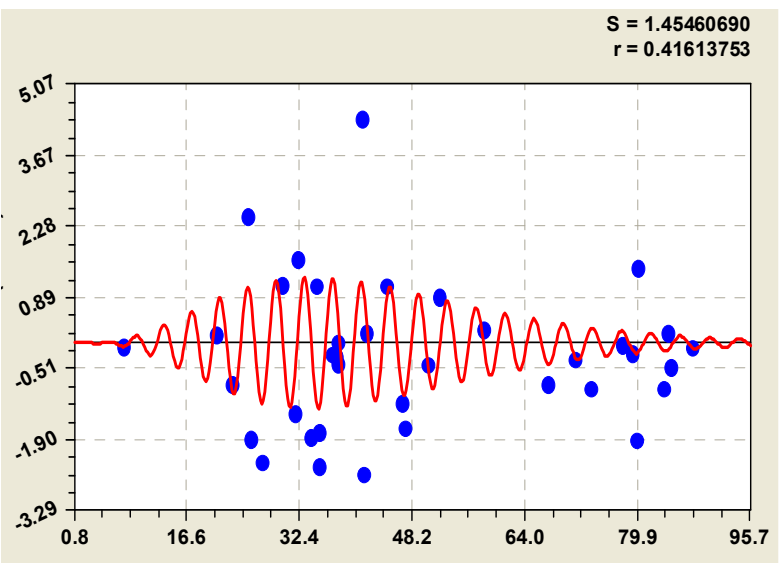

f) crisis on the eighth wave

Figure 8. Additional to the model (6) adaptation and crisis wave.

The third adaptation (fig. 8c) happened on expression

$$
\varsigma_{6}=\mathrm{A}_{5} \cos \left(\pi \xi / \mathrm{p}_{5}-1.71299\right),
$$

$$
\mathrm{A}_{5}=1.0430 \cdot 10^{-10} \xi^{8.30052} \exp \left(-0.11773 \xi^{1.11605}\right),
$$

$$
\mathrm{p}_{5}=2.13681-0.0017717 \xi^{0.72567} \text {. }
$$


The fourth adaptation took place (fig. 8d) on the wave equation

$$
\begin{gathered}
\varsigma_{7}=\mathrm{A}_{6} \cos \left(\pi \xi / \mathrm{p}_{6}-0.054939\right) \\
\mathrm{A}_{6}=0.00031957 \xi^{4.32976} \exp \left(-0.38203 \xi^{0.80143}\right) \\
\mathrm{p}_{6}=1.08772+0.0010660 \xi^{1.19734}
\end{gathered}
$$

The third crisis wave taking into account the first, earlier found two wave working out the equations (6) in figure $8 \mathrm{e}$ the crisis equation is shown

$$
\begin{gathered}
\varsigma_{8}=-\mathrm{A}_{7} \cos \left(\pi \xi / \mathrm{p}_{7}-6.14360\right) \\
\mathrm{A}_{7}=1.9079 \cdot 10^{-22} \xi^{17.9898} \exp \left(-0.27366 \xi^{1.09016}\right), \\
\mathrm{p}_{7}=0.38620 .
\end{gathered}
$$

The eighth component receives the constant frequency of fluctuation.

It appeared that Verhoshizhemsky and Sloboda rural areas have equal woodiness of $55.4 \%$. However at them, respectively, plowing of the territory is equal 28.4 and $17.1 \%$. This difference in $28.4-17.1=11.3 \%$ is also shown by the program CurveExpert-1.38.

The fourth crisis wave turned out after an exception of these two rural areas (fig. 8f) in the form of model of crisis indignation of a look

$$
\begin{gathered}
\varsigma_{9}=-\mathrm{A}_{8} \cos \left(\pi \xi / \mathrm{p}_{8}+0.33343\right) \\
\mathrm{A}_{8}=5.0120 \cdot 10^{-5} \xi^{4.16535} \exp \left(-0.17636 \xi^{0.92042}\right) \\
\mathrm{p}_{8}=1.89268+0.0079272 \xi^{0.58743}
\end{gathered}
$$

On character of an arrangement of the remains it was visible that also the subsequent wave components of model are possible. However the maximum relative error already came nearer to an error of measurements of the area of the territory. Therefore there is no need for further building of a design of the general statistical regularity. It is clear, that in the Kirov region woodiness parameter still influences change of coefficient of a plowing of the territory.

\section{Crisis Dynamics of Ruble Exchange Rate}

The fragment of tabular model for an identification of function of type $\mathrm{K}=\mathrm{f}(\mathrm{t}$ ) is given in table 2 (on days from 06.01.1993 till 31.12.2004 only 2522 supervision) [7]. For 06.01 .1993 value of the explaining variable $t=0$.

Table 2. Tabular model of dynamics of ruble exchange rate to dollar from 06.01.1993 for 31.12.2004.

\begin{tabular}{lll}
\hline Date & t, day & $\mathrm{K}, \mathbf{r u b} / \mathbf{S}$ \\
\hline 22.01 .1993 & 22 & 493.0000 \\
20.01 .1993 & 20 & 474.5000 \\
15.01 .1993 & 15 & 442.0000 \\
\hline
\end{tabular}

\begin{tabular}{lll}
\hline Date & $\mathrm{t}$, day & $\mathrm{K}, \mathbf{r u b} / \mathbf{\$}$ \\
\hline$\ldots$ & $\ldots$ & $\ldots$ \\
08.01 .2004 & 4066 & 29.2450 \\
06.01 .2004 & 4064 & 29.4545 \\
05.01 .2004 & 4063 & 29.4545 \\
\hline
\end{tabular}

The main model of crisis of ruble is received by computing opportunities of the program environment CurveExpert-1.40 (fig. 9, fig. 10) in the form of a formula

$$
\begin{gathered}
\mathrm{K}=\mathrm{K}_{1}+\mathrm{K}_{2}+\mathrm{K}_{3}+\mathrm{K}_{4}+\mathrm{K}_{5}, \\
\mathrm{~K}_{1}=1596.1347 \exp (-0.0028496 \mathrm{t}), \\
\mathrm{K}_{2}=1.26648 \cdot 10^{-16} \mathrm{t}^{7.47867} \exp \left(-0.0031169 \mathrm{t}^{1.10028}\right), \\
\mathrm{K}_{3}=\mathrm{A}_{1} \cos \left(\pi \mathrm{t} / \mathrm{p}_{1}-2.55294\right), \\
\mathrm{A}_{1}=-5.52024 \cdot 10^{-23} \mathrm{t}^{9.43835} \exp \left(-0.0036385 \mathrm{t}^{1.07839}\right), \\
\mathrm{p}_{1}=288.21469+758.00773 \mathrm{t}^{0.020296} \exp \left(-0.00020804 \mathrm{t}^{1.08303}\right) \\
\mathrm{K}_{4}=\mathrm{A}_{2} \cos \left(\pi \mathrm{t} / \mathrm{p}_{2}+3.09398\right), \\
\mathrm{p}_{2}=371.72980, \mathrm{~K}_{5}=\mathrm{A}_{3} \cos \left(\pi \mathrm{t} / \mathrm{p}_{3}+0.20634\right), \\
\mathrm{A}_{3}=23035.3488(\mathrm{t}-1825.8462)^{-1}, \mathrm{p}_{3}=22.28533 .
\end{gathered}
$$

Each component (13) makes physical (economic) sense.

The first component under the law of exponential death (Pareto's law in economy, Zipf in biology, Mandelbrot in physics and Laplace in mathematics) shows natural aspiration of the Russian economic system to decrease by 06.01 .1993 in the gathered course of domestic currency $\mathrm{K}_{0}=417 \mathrm{rub} / \$$. The second component under the biotechnical law shows stressful excitement of the Russian financial system.

Together two components give a trend in the form of not the wave (determined) binomial formula (fig. 9).

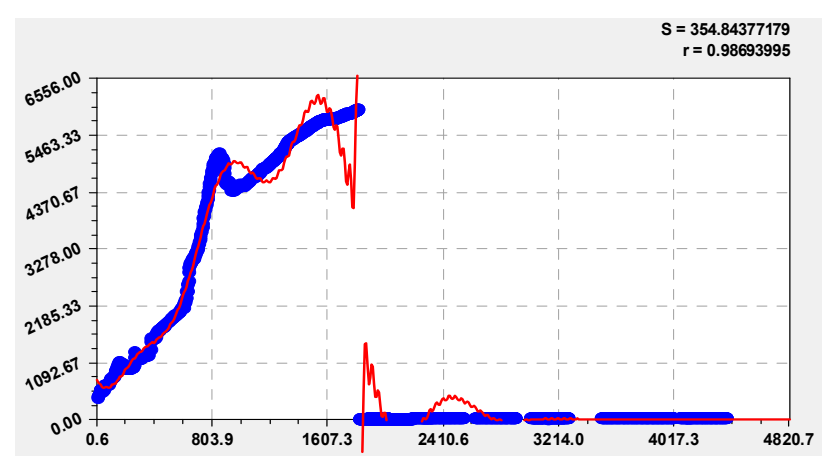

Figure 9. The schedule of statistical model (13) of dynamics of ruble exchange rate during the crisis period.

Other three members are wave functions which define computing approaches of quantum informatics in some sense. But, despite a rupture of the actual ruble exchange rate because of denomination by 1000 times, us it was proved that is possible to describe a default smooth functions. Thereby once again is confirmed that social and economic crisis of any power can be described statistical models on good quality 
selections.

The third component in the form of mega fluctuation is the main, showing chaotic while clearly unwitting economic management. This oscillatory indignation nearly brought to collapse and is similar to behavior of obviously upset natural biological systems.

The fourth and fifth components show a ruble default. This process of a default us is described by a type hyperbole
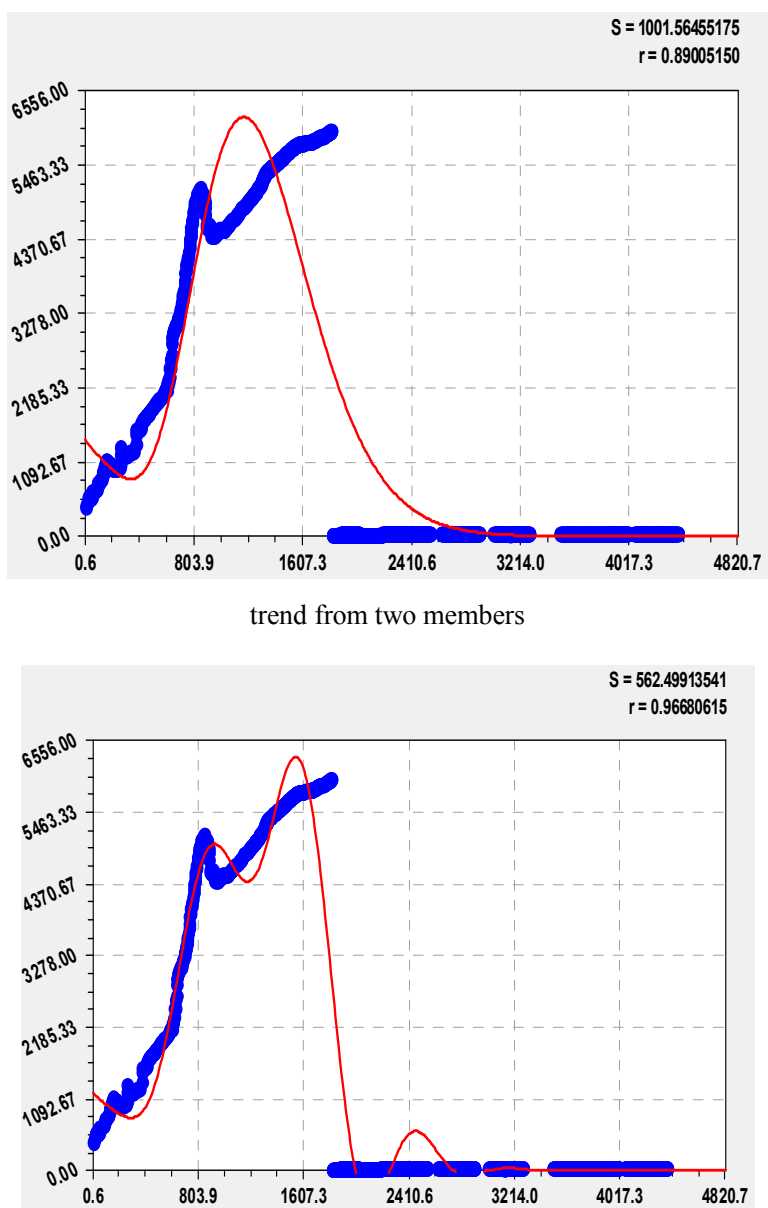

trend and first wave

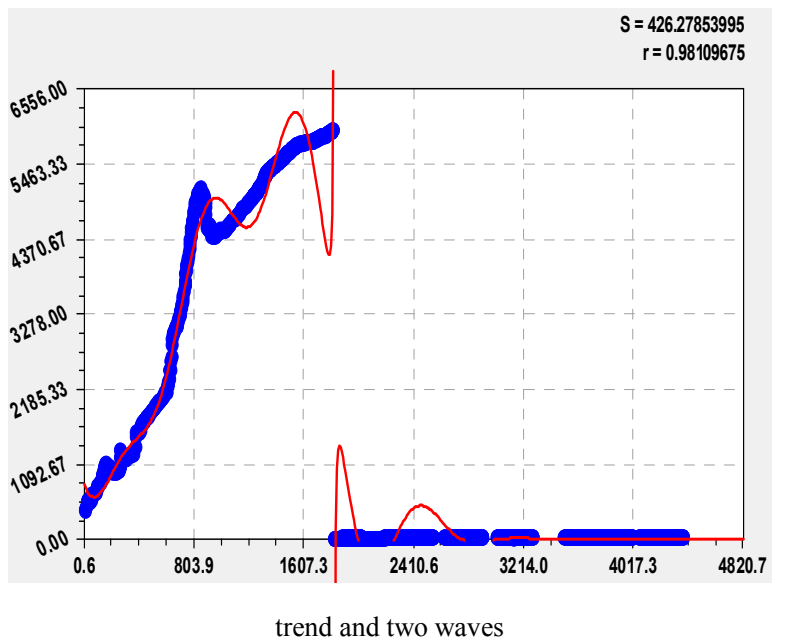

$$
\mathrm{y}=\mathrm{k} / \mathrm{x}
$$$$
\mathrm{k}=-\mathrm{a} \exp \left(-\mathrm{bt}^{\mathrm{c}}\right) \cos (\pi \mathrm{t} / \mathrm{d}+\mathrm{e}), \mathrm{x}=\mathrm{t}-1826.3984
$$

where a, b, c, d, e - the parameters of model (14) identified in the program environment.
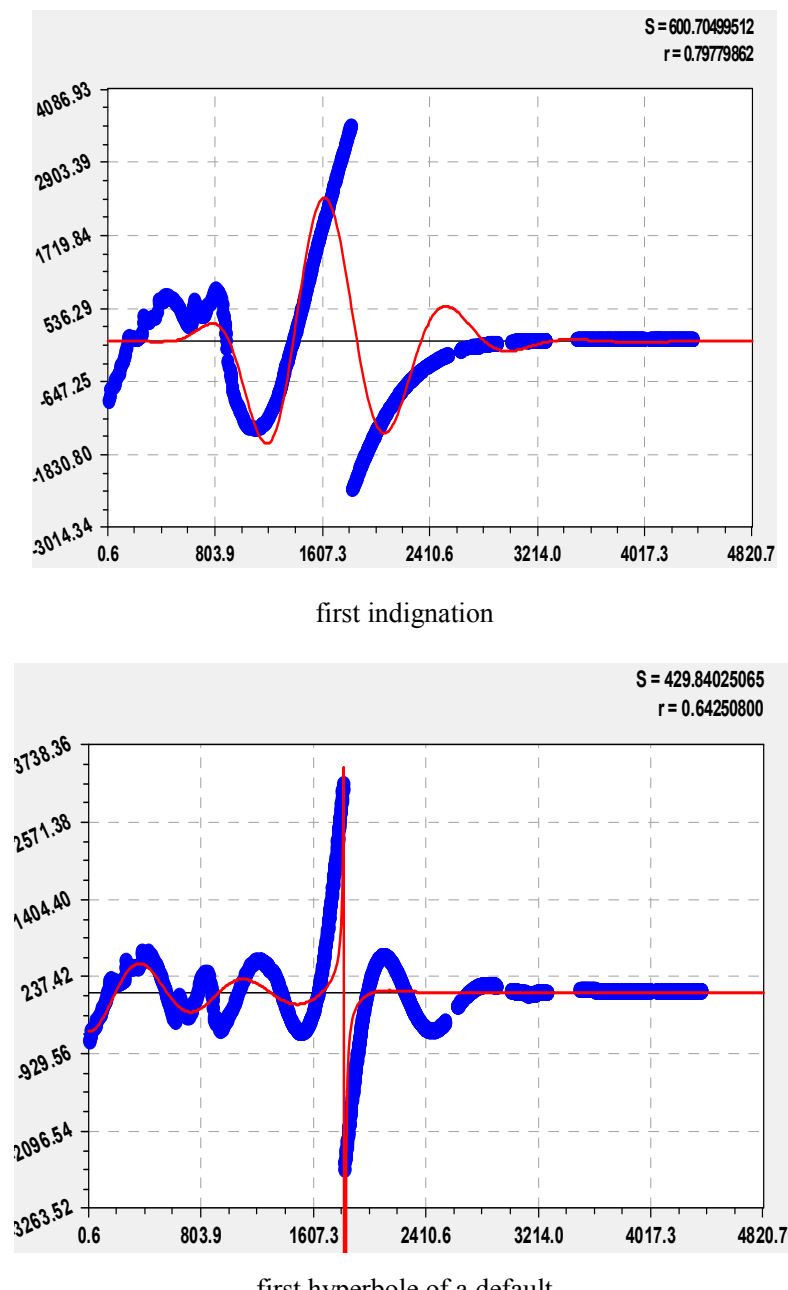

first hyperbole of a default

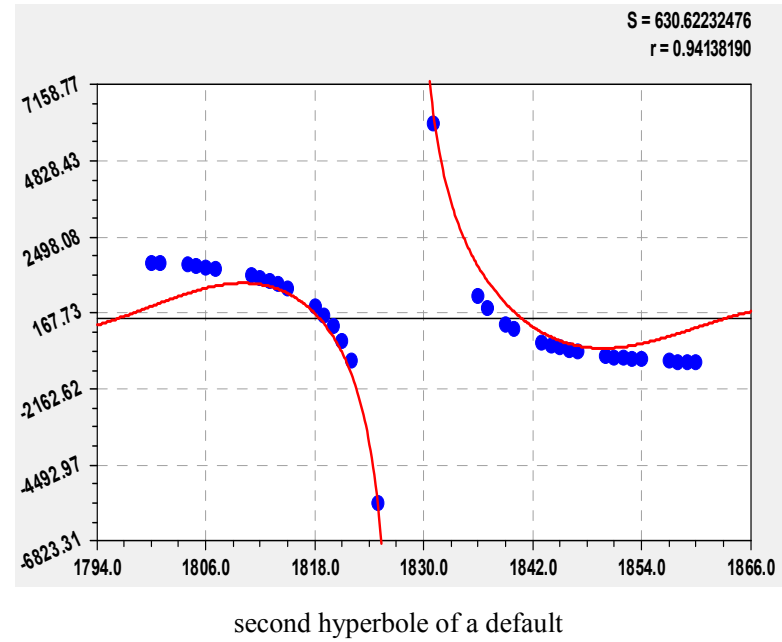

Figure 10. Schedules of separate components of model (13). 
In figure 10 the third wave of hyperbolic fluctuation is shown for the points which are near date of a default and it is characterized by a formula (14) with model parameters:

$$
\begin{gathered}
\mathrm{a}=23035.3488 \mathrm{rub} / \mathrm{S}, \mathrm{b}=0, \mathrm{c}=0, \mathrm{~d}=\mathrm{p}_{3}=22.28533 \\
\text { day, } \mathrm{e}=1825.8462 \text { days. }
\end{gathered}
$$

From a formula (13) it is visible that there were two defaults. If not urgent measures of financial stabilization, on elements of the third member ruble exchange rate would reach the level of $1.50797106 \mathrm{rub} / \$$ in the beginning, and then 23035.35 $\mathrm{rub} / \mathrm{\$}$. On 06.01 .1993 the periods are equal: $2 \mathrm{p}_{1}=2 \times 288.21462 \approx 576.4 ; 2 \mathrm{p}_{2}=743.5 ; 2 \mathrm{p}_{3}=44.6$ days.

\section{Patenting Volume in Russia}

The number of patents for intellectual property in our country changes [12] according to schedules in figure 11 on a
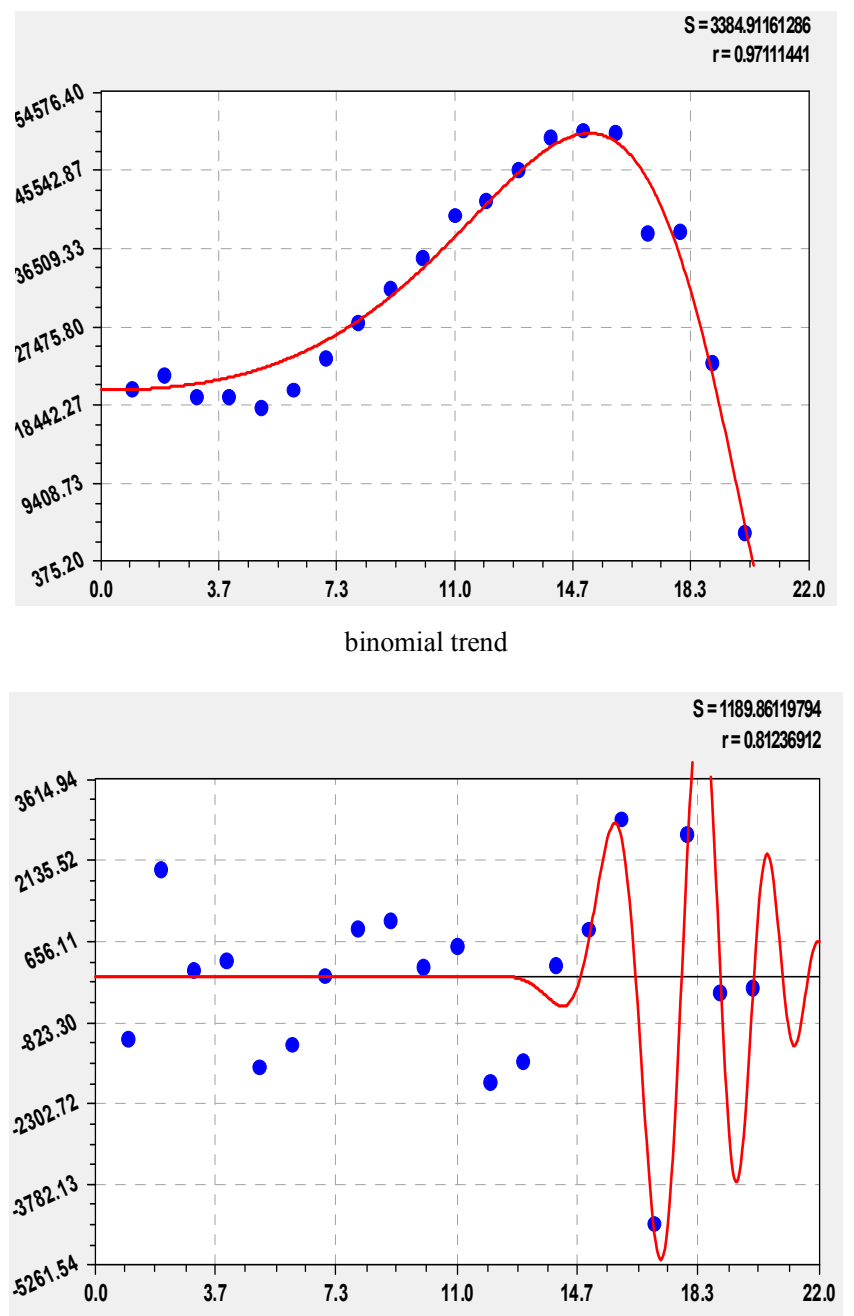

second wave indignation formula

$$
\mathrm{N}_{\mathrm{RU}}=\mathrm{N}_{1}+\mathrm{N}_{2}+\mathrm{N}_{3}+\mathrm{N}_{4},
$$

$$
\mathrm{N}_{1}=20137.366 \exp \left(0.0029067 \mathrm{t}^{2.29800}\right) \text {, }
$$$$
\mathrm{N}_{2}=-3.70339 \cdot 10^{-5} \mathrm{t}^{7.65749},
$$$$
\mathrm{N}_{3}=\mathrm{A}_{1} \cos \left(\pi \mathrm{t} / \mathrm{p}_{1}+0.80687\right) \text {, }
$$

$A_{1}=12501.360 \exp \left(-0.90186 t^{0.29987}\right)$,

$\mathrm{p}_{1}=7.24097-0.00026170 \mathrm{t}^{3,06616}$,

$$
\mathrm{N}_{4}=\mathrm{A}_{2} \cos \left(\pi \mathrm{t} / \mathrm{p}_{2}+3.66117\right),
$$

$$
\begin{gathered}
\mathrm{A}_{2}=7.22653 \cdot 10^{-68} \mathrm{t}^{85.17581} \exp \left(-4.13391 \mathrm{t}^{1.03752}\right), \\
\mathrm{p}_{2}=6.15466-0.20497 \mathrm{t}^{0.96942}
\end{gathered}
$$

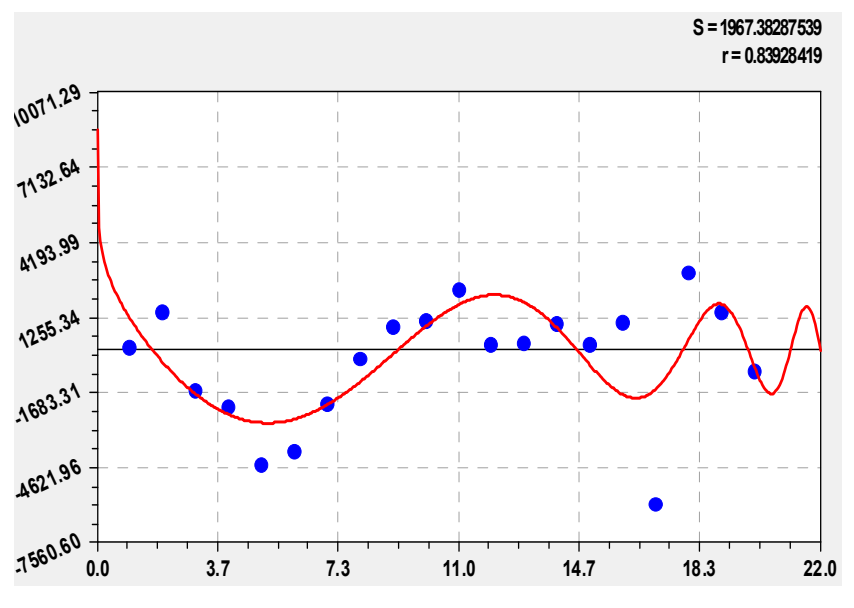

first wave indignation

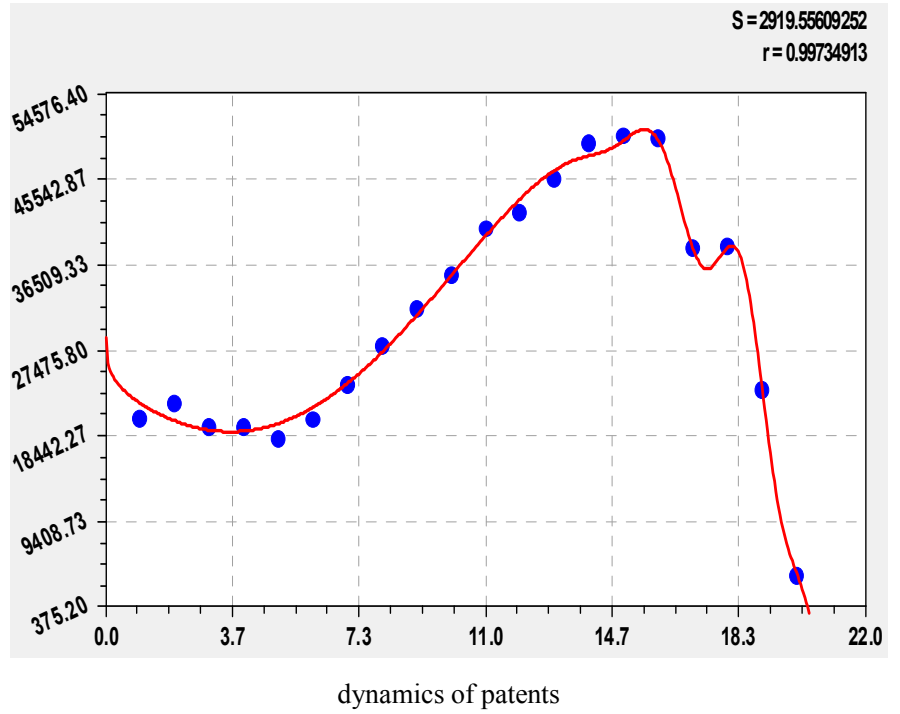

$=2919.55609252$

Figure 11. Dynamics of number of patents in Russia in 1992-2012. 
component shows crisis (a negative sign before the member) change of number of the Russian patents. As a result of binomial trend in figure 1 receives a tendency of some increase from 1998 to 2007. But after 2007 the second component starts exceeding sharply the natural first member of the equation (15). Understanding of the strongest crisis in innovative development of the country in the second member of the equation (15) would allow to take effective measures and to reduce rates of recession of volume of patenting. Both fluctuations positive (a positive sign before components), amplitude of the first fluctuation has recession, and the second - nature of stressful excitement. Thus the first wave indignation sharply becomes frequent on the frequency that shows controllability loss by innovative processes.

At a half-cycle of 7.24 years increase will reach till one year in 2019 and further will become negative on value (a half of amplitude will become equal only 1108 pieces). Influence of the first fluctuation since 2020 can be neglected. The second fluctuation will end in 2015.

If genotypic distance from a prototype to the invention isn't raised, according to the forecast a formula (15) patenting volume will sharply increase, but thus patents won't raise a world technological level of the let-out domestic production.

As a result of, as before, more than $70 \%$ of patents will be sent on obsolete to the technician and technology. Since 2017 the volume of patenting will reach till crisis 2007, but each patent will have very small increments on novelty, complexity of a technical solution. For radical reform of the industry and
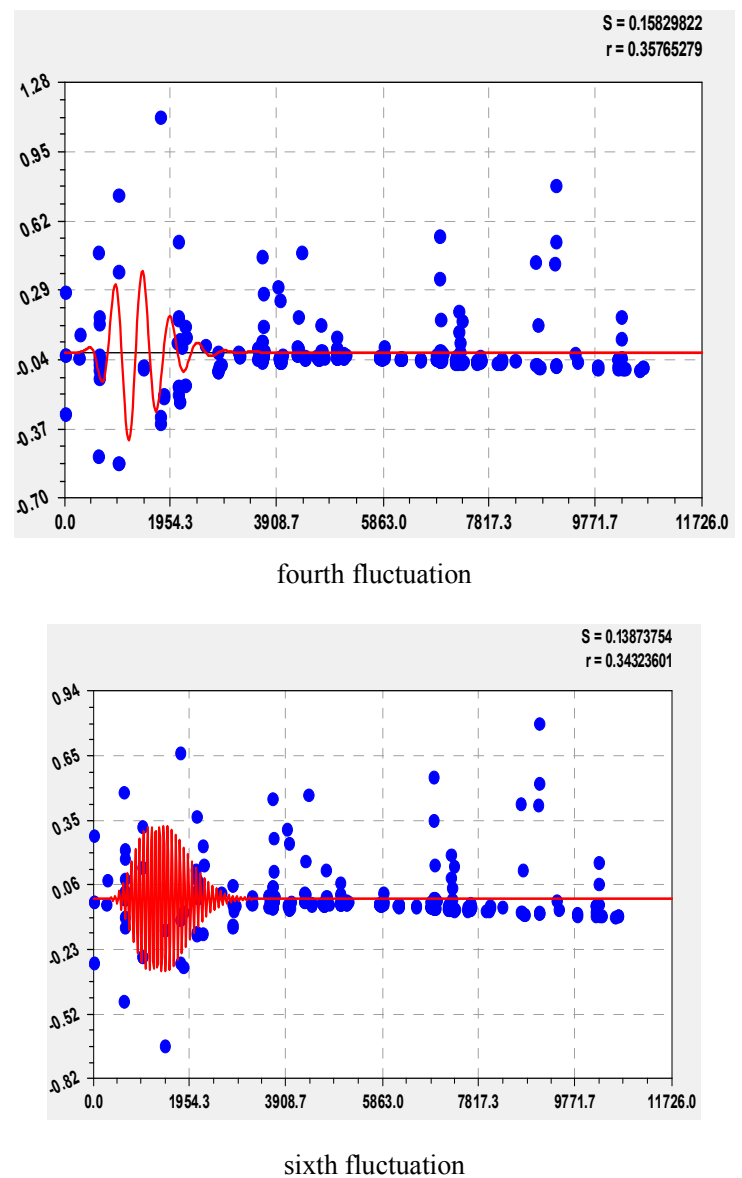

the valid transition to an innovative way of development of the country and growth of technological base of economy remained only $2017-2014=3$ years.

\section{Dynamic number of Forest Fires as Series of Signals}

As an example in figure 12 schedules of the physical and mathematical analysis of dynamics of forest fires for 1982-2011 in «Mary Chodra» on several wavelets are shown (models aren't given). And on the revealed regularities it would be possible to execute the indicative inertial forecast for the forecast horizon equal to the forecast basis (to a period from zero before the last measurement of forest fire), and also the working inertial forecast for one third of the period of last measurements of forest fires. As a result efficiency of suppression of the fires increases. Application of the offered method $[15,18,20]$ expands possibilities of territorial environmental monitoring, increases functionality of system like «Forest Patrol».

Consider one of the affected forest block 27 Alchick. For mathematical analysis left only the strong biotechnical regularities and the correlation coefficient is not less than 0.7 . The total period of measurements with 27.07.1992 on 22.05.1994 is only $4282-3648=634$ days. In such a short period of less than two years on the forest block 27 only 9 forest fires.
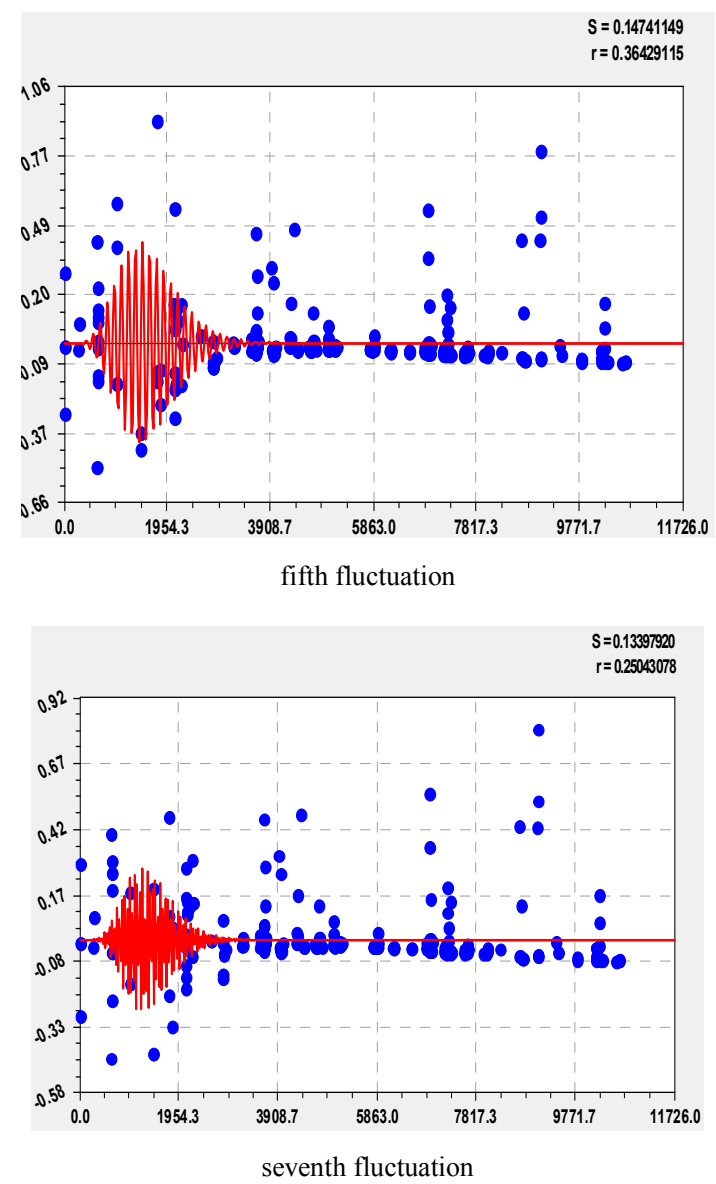

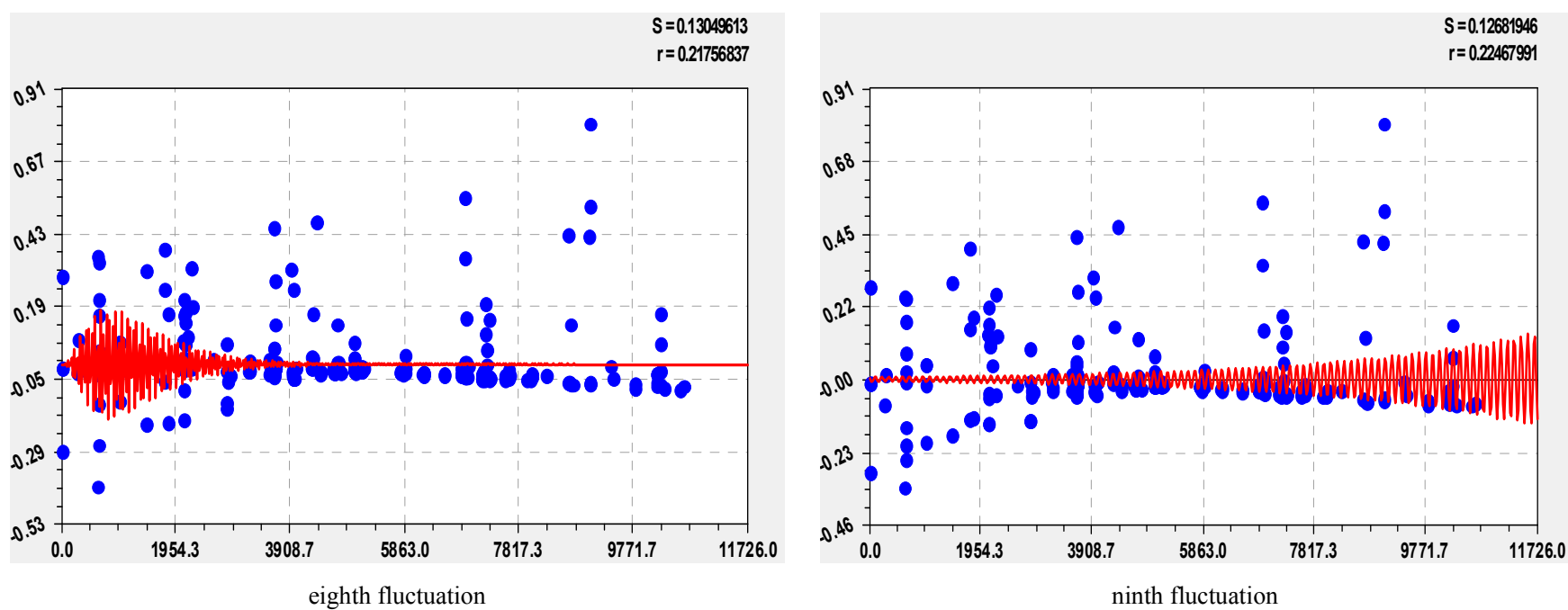

Figure 12. Schedules of separate asymmetric wavelet signals from the general statistical model of dynamics of the area of forest fires from measurement time in days during 1982-2011.

The period of the fire extinguishing efficiency (fig. 13) is determined by the formula

$$
\begin{gathered}
\eta=77,30308 \exp (0,012735 \mathrm{~T})+ \\
+6,36117 \mathrm{~T}^{6,51805} \exp (-2,19802 \mathrm{~T})
\end{gathered}
$$

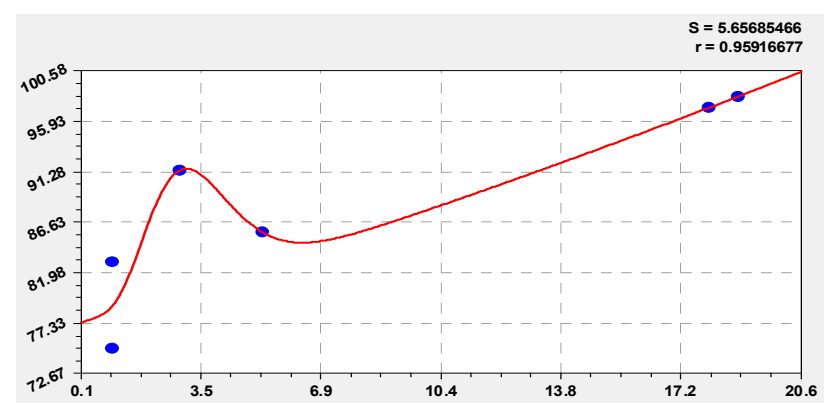

Figure 13. A graph of the influence of the period of forest fire extinguishing efficiency at quarter 27.

The graph shows that with the growth period of the fire increases the efficiency of quenching, i.e. the personnel of the fire service forestry starting to become more active with a greater intensity. The first component of the trend is the exponential growth. The forestry staff is focused on stress arousal (the second component of the trend in biotechnological law), when the period of the fire changes from one to seven hours.

\section{Alpha Decay at a Solar Eclipse}

Influence of three celestial bodies of the Sun, Earth and the moon on intensity of hour increments of alpha activity of a sample ${ }^{239} \mathrm{Pu}$ are shown in articles [3-6]. For example, after identification the formula was received (fig. 14) five-membered (on a limit of opportunities of the program
CurveExpert environment)

$$
\begin{aligned}
& \mathrm{I}_{\mathrm{u}}=\mathrm{I}_{\mathrm{q} 1}+\mathrm{I}_{\mathrm{q} 2}+\mathrm{I}_{\mathrm{ч} 3}+\mathrm{I}_{\mathrm{q} 4}+\mathrm{I}_{\mathrm{u} 5}, \\
& I_{41}=11333.009, \quad I_{42}=13.72924 t, \\
& \mathrm{I}_{\mathrm{u} 3}=\mathrm{A}_{1} \cos \left(\pi \mathrm{t} / \mathrm{p}_{1}+0.85630\right), \\
& A_{1}=-1259.6144 \exp (-0.049053 t), \\
& \mathrm{p}_{1}=13.83259-0.059446 \mathrm{t}^{1.08961} \\
& \mathrm{I}_{\mathrm{\varphi} 4}=\mathrm{A}_{2} \cos \left(\pi \mathrm{t} / \mathrm{p}_{2}+1.50517\right), \\
& \mathrm{A}_{2}=4.28216 \cdot 10^{-39} \mathrm{t}^{26.52258} \exp \left(-0.0063403 \mathrm{t}^{1.67090}\right), \\
& \mathrm{p}_{2}=2.18104, \mathrm{I}_{\mathrm{q} 5}=\mathrm{A}_{3} \cos \left(\pi \mathrm{t} / \mathrm{p}_{3}-5.20128\right), \\
& \mathrm{A}_{3}=-302.03608 \mathrm{t}^{0.22076}, \\
& \mathrm{p}_{3}=-7.67903+9.05505 \mathrm{t}^{0.058383},
\end{aligned}
$$

where $\mathrm{t}$ - time in hours, beginning of 04-05 o'clock on April $07,2005, I_{ч}-$ sentries of excess of number of impulses, $I_{ч 1}$, $\mathrm{I}_{42}, \mathrm{I}_{43}, \mathrm{I}_{44}$ and $\mathrm{I}_{\mathrm{4} 5}$ - components of the model (17), $\mathrm{A}_{1}, \mathrm{~A}_{2}$ and $\mathrm{A}_{3}$ - amplitudes (half) of the first, second and third oscillatory indignation of a gravitational wave, $\mathrm{p}_{1}$, $\mathrm{p}_{2}$ и $\mathrm{p}_{3}$ - half-cycles of fluctuations of alpha decay of a sample $239 \mathrm{Pu}$. 

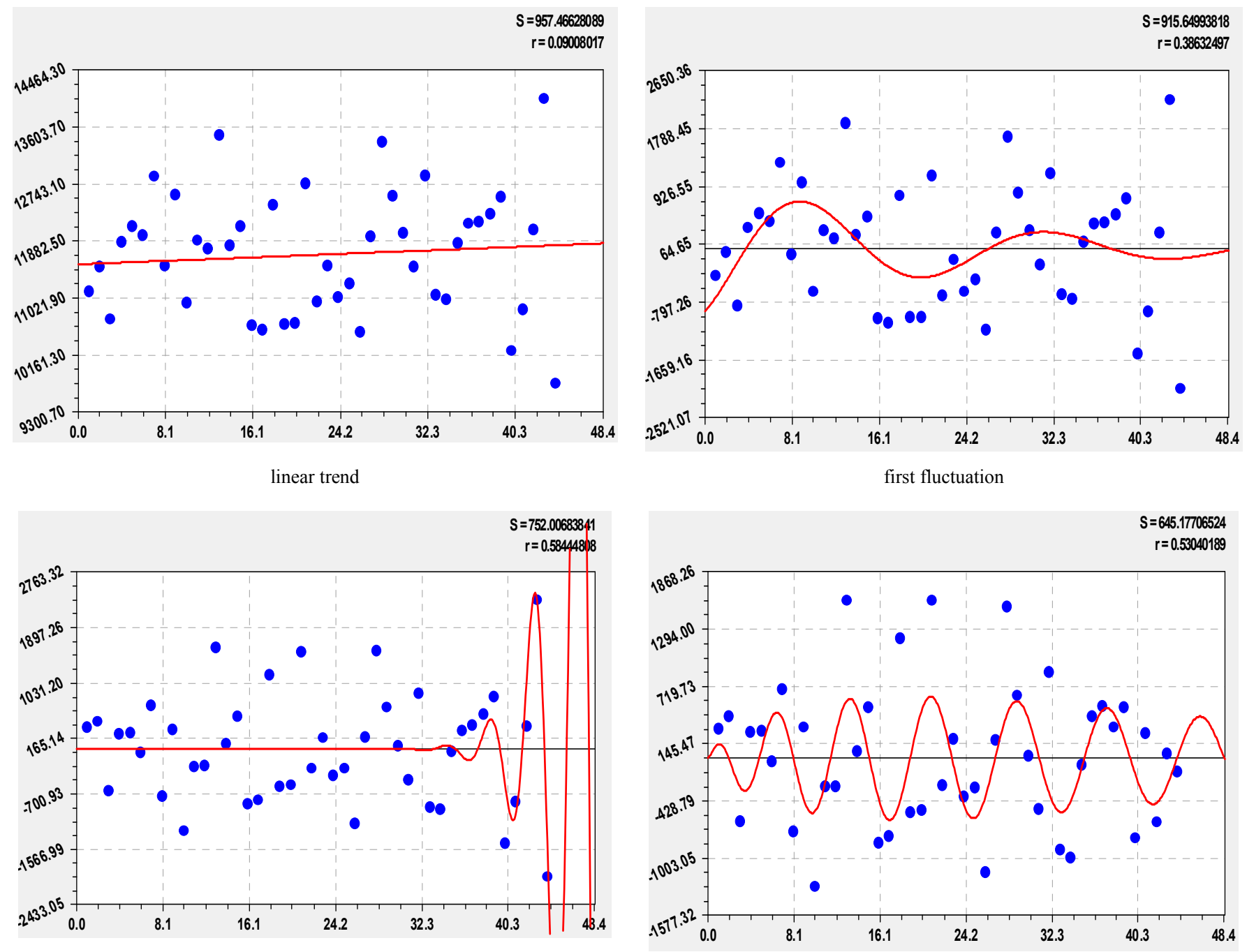

second fluctuation

third fluctuation
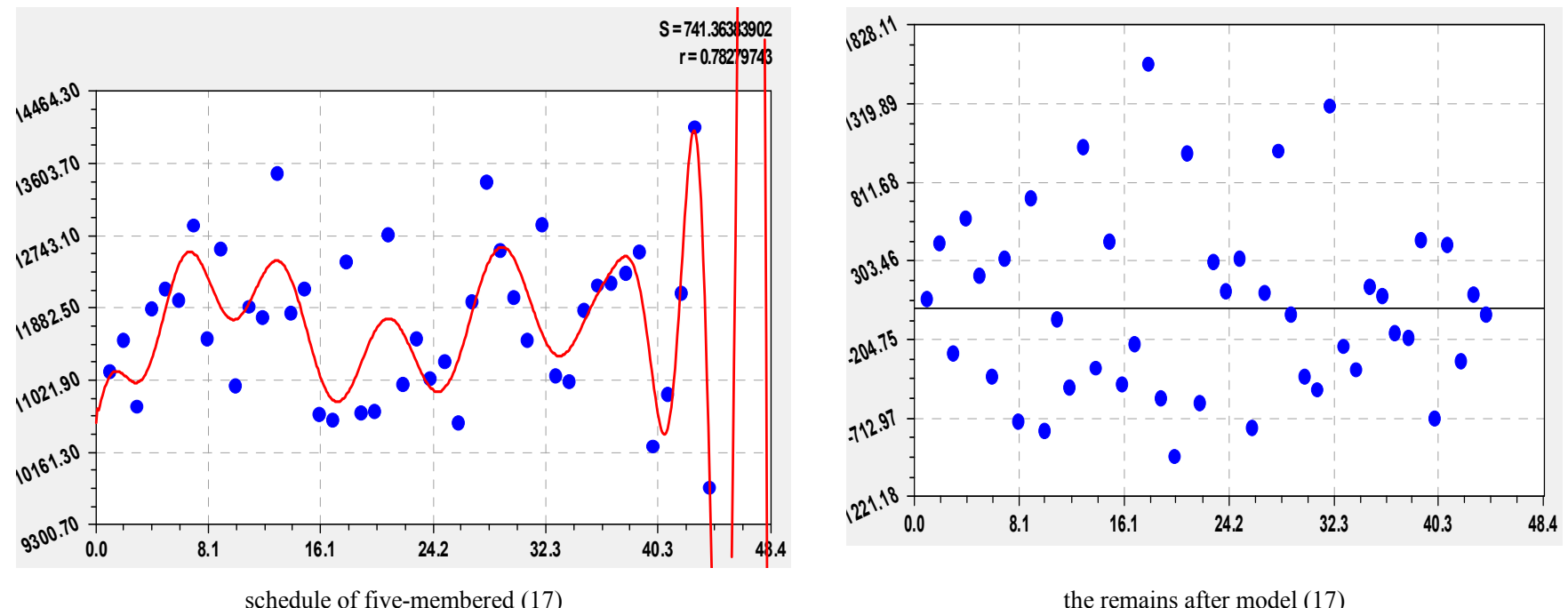

the remains after model (17)

Figure 14. Dynamics of hour impulses of alpha decay at a maximum of a solar eclipse.

In a formula (17) the first component received constant value, and the second member has linear change. The initial stage for three fluctuations is respectively equal $2 \times 13.83259$ $\approx 27.7,2 \times 2.18104 \approx 5.1=$ const and $-2 \times 7.67903 \approx$ $-15.4 \mathrm{~h}$.

The general model of dynamics of hour increments of 
impulses includes 43 members.

\section{Fractal Analysis of Wavelets}

The quantity of impulses of radioactive decay always exceeds $I_{0}=300 \mathrm{c}-1$. Therefore for fractal group we will enter levels $U=I_{\text {ч }}^{\text {ост }} / I_{0} \quad[3-6]$.

Zero level is equal to the maximum rest of $\left|\varepsilon_{\max }\right|=14034$ hour increments of impulses divided on 300, i.e. $\mathrm{U}_{0}=\mathrm{I}_{\mathrm{q}}^{\max } / \mathrm{I}_{0}=14034 / 300=46.8$.

After identification the formula of rank decrease in the maximum remains $\left|\varepsilon_{\max }\right|$ in the form of the binomial equation was received

$$
\begin{aligned}
\left|\varepsilon_{\max }\right| & =16333.904 \exp (-2.08048 R)- \\
- & A \cos (\pi R / p+1.29249) \\
A & =8397.012 \exp (-0.33912 R)
\end{aligned}
$$
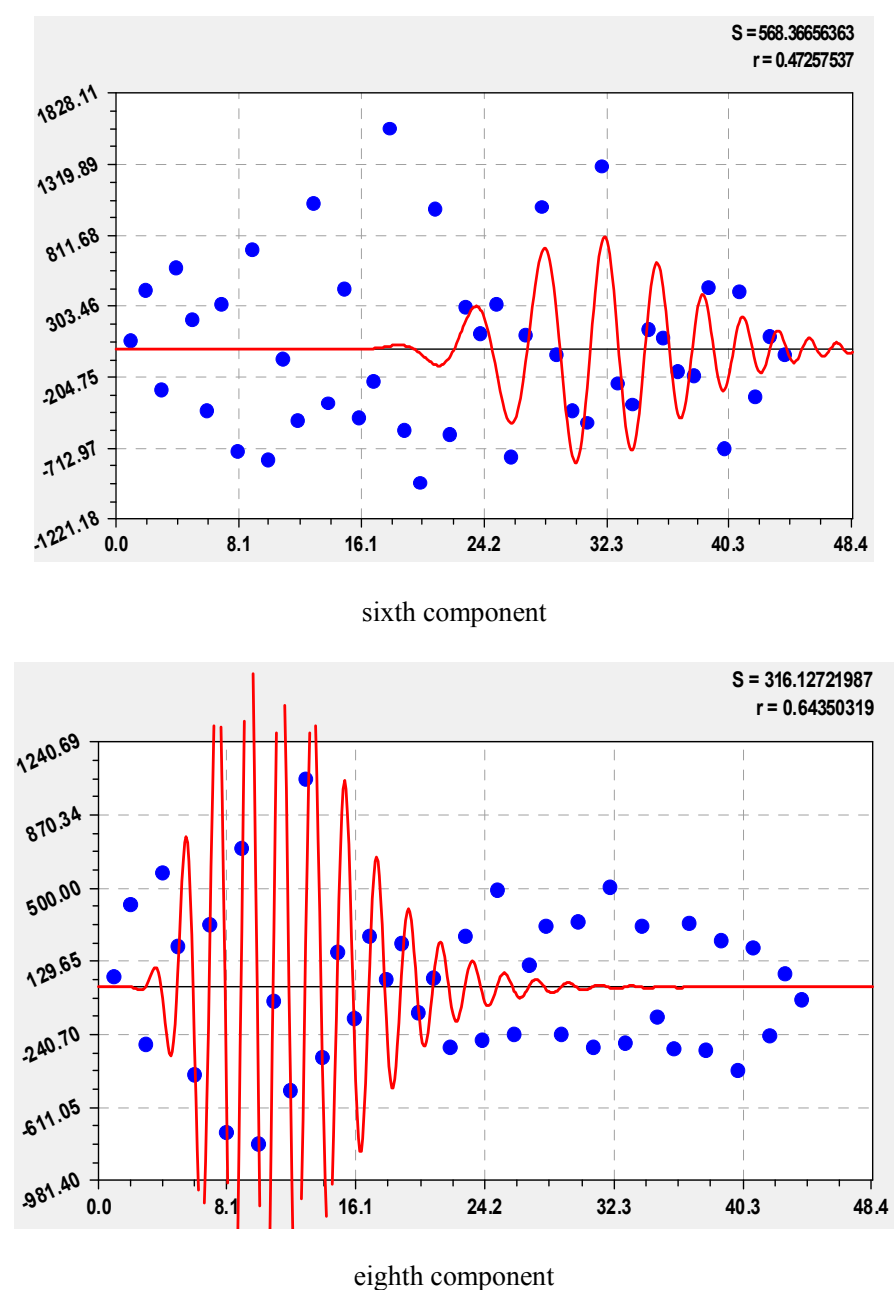

$$
\mathrm{p}=9.51595+0.059570 \mathrm{R}^{1.75114} \text {. }
$$

The first member is Mandelbrot's law for fractal decomposition. The remains show that within ranks $0-11$ one more wave indignation of parameters of models of wavelets is possible. Further models settle down more quietly.

\section{Fractals of a Maximum of a Solar Eclipse}

The model includes three fractal levels [5]. The first level is equal $\mathrm{U}_{1}=7.4$. Then decrease with turns out 46.8 to 7.4 by 6.3 times. The second level of fractal group at $\mathrm{U}_{2}=5.3$ corresponds to three waves at ranks $\mathrm{R}=3,4,5$.

All members of model have correlation coefficient more than 0.3 and therefore each wave regularity is significant.

In figure 15 schedules of members with ranks 6-11 are given.

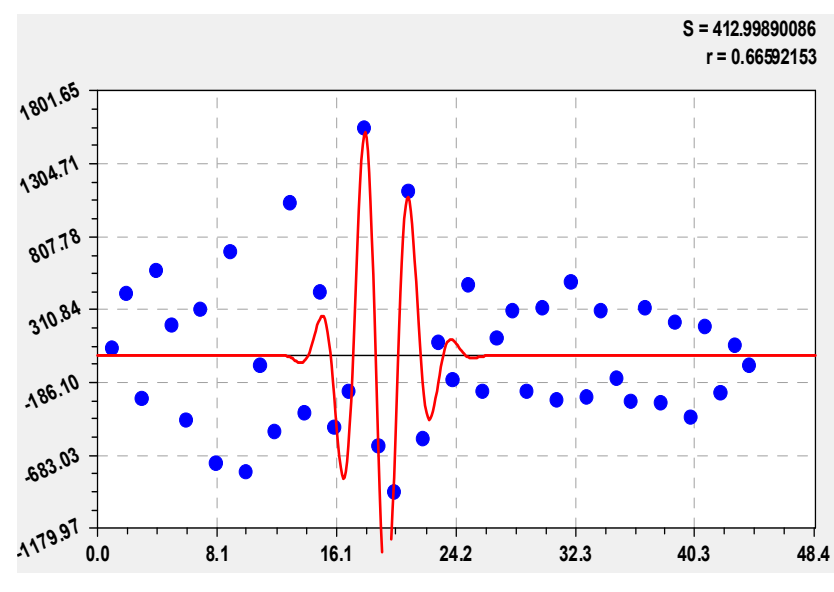

seventh component

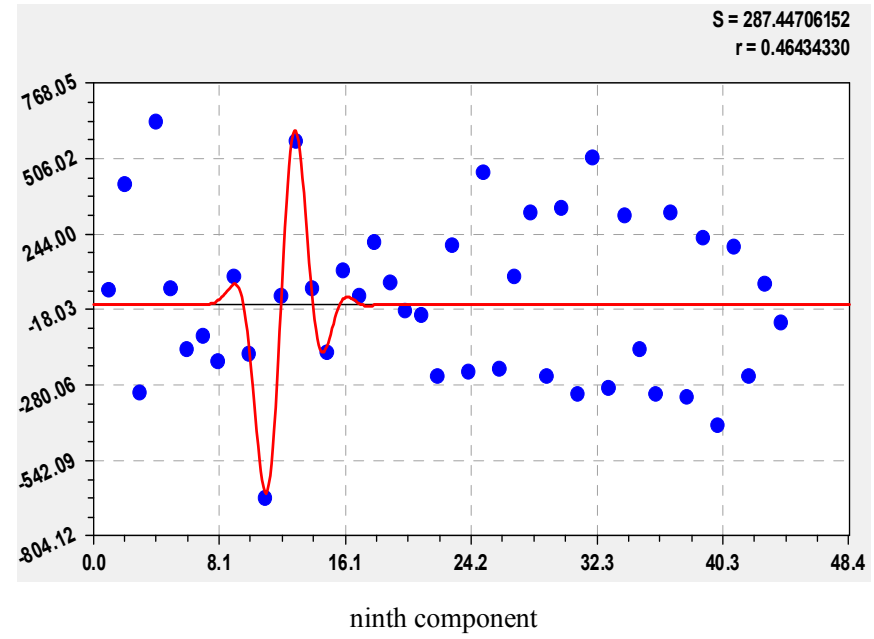



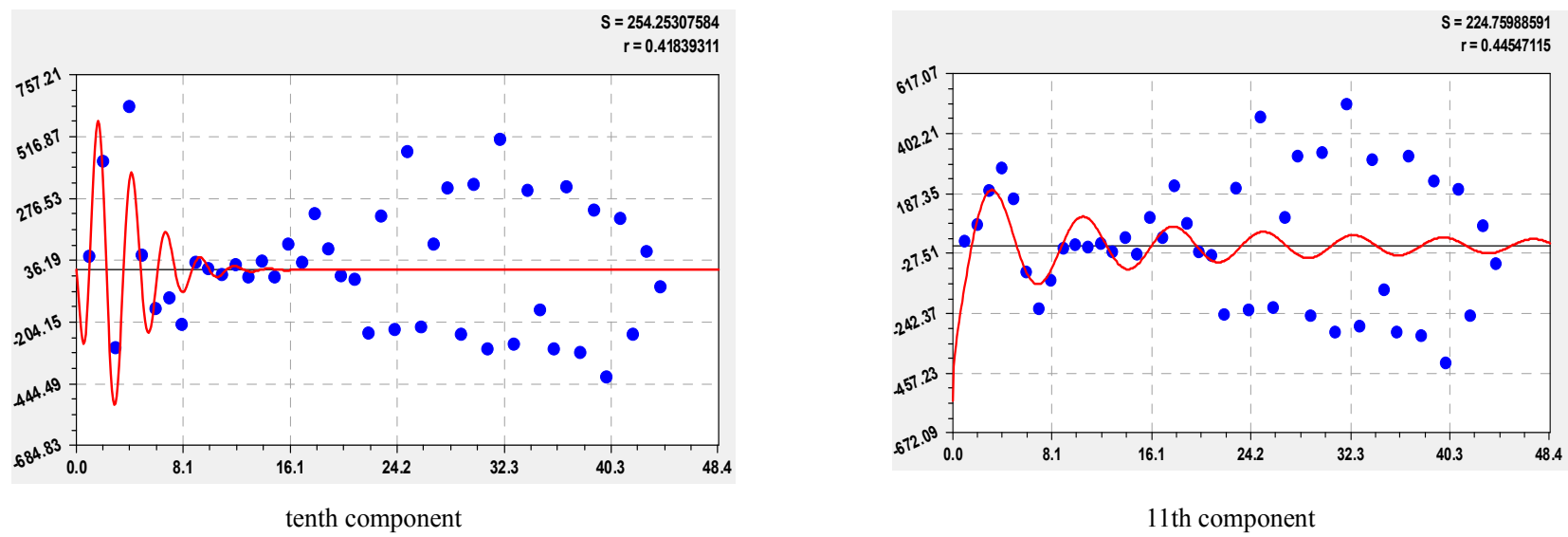

Figure 15. Dynamics of hour impulses of alpha decay at a maximum of a solar eclipse.

Thus the 11th component as if closes group, receiving amplitude under the law of exponential death. This fact means that the stage of a maximum of solar activity is influenced by the previous stage of a laminar phase. Therefore all wavelets are interconnected on a time scale by infinite wavelets. And finite-dimensional wavelets show a stage or part of the general process.

The last wavelet signal received coefficient of correlation 0.8041 and it refers regularity №43 in group with strong factorial communications. Thus, we proved possibility of statistical modeling of indignations of gravitational waves from action of a maximum of a solar eclipse.

\section{Model of the Lapping Universe}

From schedules in figure 16 it is visible that gravitational oscillatory indignation of star systems on amplitude $h$ happens in the range of a cycle time of pulsars 0.1-1.0 days.
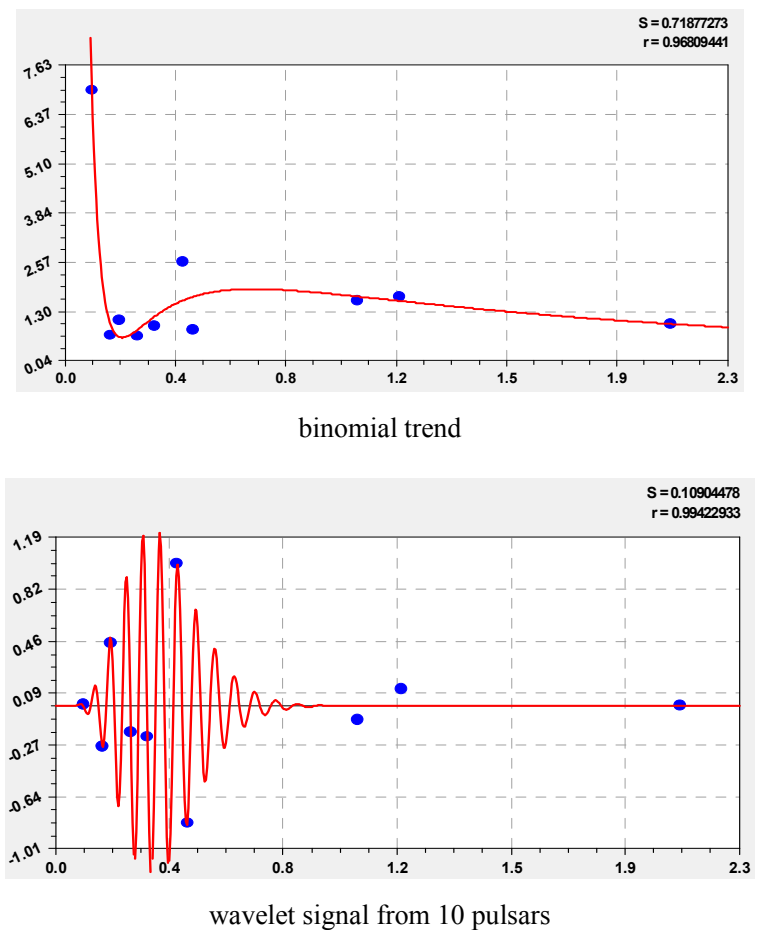
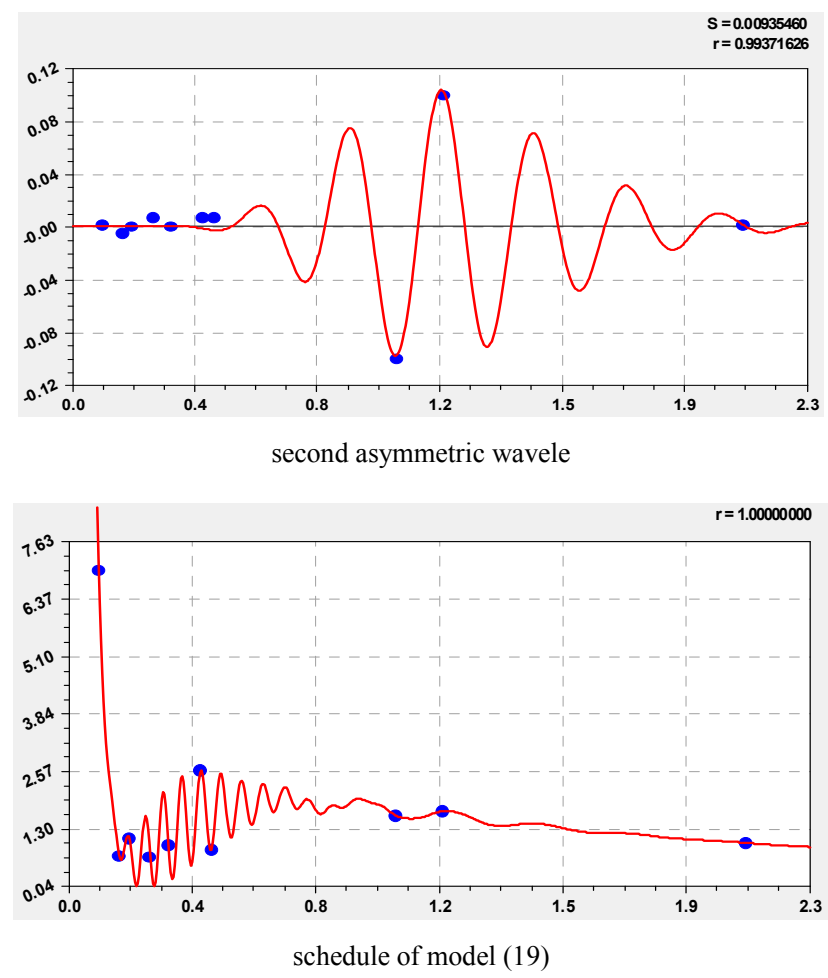

Figure 16. The schedule of statistical model (19) of change of amplitude of gravitational.

All four members give model of the lapping Universe (fig. 16) of a look

$$
\begin{gathered}
10^{22} \mathrm{~h}_{0}=\mathrm{h}_{01}-\mathrm{h}_{02}-\mathrm{h}_{03}+\mathrm{h}_{04}, \\
\mathrm{~h}_{01}=10045843.0 \exp \left(-13.119916 \mathrm{~T}^{0.12626636}\right), \\
\mathrm{h}_{02}=756195.75 \exp \left(-10.623253 \mathrm{~T}^{0.16669093}\right), \\
\mathrm{h}_{03}=\mathrm{A}_{1} \cos \left(\pi \mathrm{T} / \mathrm{p}_{1}-1.9456439\right), \\
\mathrm{A}_{1}=8808164.2 \mathrm{~T}^{6.9036732} \exp \left(-20.080126 \mathrm{~T}^{0.7992200}\right), \\
\mathrm{p}_{1}=0.024095462+0.0073109174 \mathrm{~T}^{1.0864200},
\end{gathered}
$$




$$
\begin{gathered}
\mathrm{h}_{04}=\mathrm{A}_{2} \cos \left(\pi \mathrm{T} / \mathrm{p}_{2}-3.2854931\right), \\
\mathrm{A}_{2}=2631.0001 \mathrm{~T}^{9.3234819} \exp (-9.7213955 \mathrm{~T}), \\
\mathrm{p}_{2}=0.13093392+0.0014765024 \mathrm{~T}^{2.122200},
\end{gathered}
$$

From a formula (19) it is visible that the periods of fluctuations of amplitude of gravitational waves under a condition $\mathrm{T}=0$ are equal at the first wavelet $2 \times 0.024095462=0.048190924$ and second fluctuation $2 \times 0.13093392=0.26186784$ (it is necessary to consider still a multiplier 10-22).

In this interval there are seven star systems, except three pulsars of PSR J0700+6418, PSR J1829+2456 and PSR J1439-5501. They are located to the right of a pointer point $1,0[8,19]$. The interval of a cycle time of pulsars in the second fluctuation changes from 0.4 to $2.2-2.3$ days. Two fluctuations are in the range of $0.4-1.0$ days.

The attitude of the second fluctuation towards the first will be equal 5.43398. Frequency of two fluctuations of a gravitational wave under a condition $\mathrm{T}=0$ at the possible pulsar which is infinitely quickly rotating theoretically will be equal $20.750805 \mathrm{e} 22$ and $3.818721 \mathrm{e} 22$.

To two aperiodic fluctuations of a trend which were expressed by the modified Laplace's laws, two asymmetric wavelet are added.

\section{Conclusions}

Applicability of statistical model (1) to any natural objects, first of all to biological [22-25] and biotechnical is proved, beginning from an impulse of heart of the person to model of the lapping Universe. For example, in gravitational waves between the Sun, Earth and the Moon in the period of a maximum of a solar eclipse there are multilevel processes which can precisely be caught on hour increments of impulses of alpha decay from a sample ${ }^{239} \mathrm{Pu}$.

And, at last, there is a group of regularities, on the remains comparable with a margin error measurements. This fact proves that the method of measurement of indignations of gravitational waves of the device with alpha decay impulses ${ }^{239} \mathrm{Pu}$ is very exact, allowing to carry out registration on separate impulses.

\section{References}

[1] Wavelets in geophysics: processing of signals in seismic exploration / A.E. Runnova, A.E. Hramov, A.A. Koronovsky, A.N. Pavlov, A.V. Ivanov. M.: University book, 2013. 190 p.

[2] Wavelet in neurodynamics and neurophysiology / A.A. Koronovsky, V.A. Makarov, A.N. Pavlov, E.Y. Sitnikova, A.E. Hramov. M.: FIZMATLIT, 2013. 272 p.

[3] P.M. Mazurkin. Wavelet analysis of alpha activity of a sample ${ }^{239} \mathrm{Pu}$ solar eclipse // Science and world: international scientific magazine. 2013. № 1(1). P. 94-104.

[4] P.M. Mazurkin. Wavelet analysis of alpha activity ${ }^{239} \mathrm{Pu}$ in time of a solar eclipse // Science and the world: international scientific magazine. 2014. № 1(5). P. 94-104.

[5] P.M. Mazurkin. Wavelet analysis of hour increments of alpha activity ${ }^{239} \mathrm{Pu}$ at a maximum of a solar eclipse // Science and the world: international scientific magazine. 2014. № 2(6). Volume 1. P. 46-55.

[6] P.M. Mazurkin. Wavelet analysis of hour increments of alpha activity ${ }^{239} \mathrm{Pu}$ after a solar eclipse // Science and the world: international scientific magazine. 2014. № 3(7). Volume 1. P. 31-40.

[7] P.M. Mazurkin. Wavelet analysis of crisis dynamics of ruble exchange rate // Interdisciplinary researches in the field of mathematical modeling and informatics. Materials of the 3rd scientific and practical Internet conference Ulyanovsk: SIMJET, 2014. P. 260-268.

[8] P.M. Mazurkin. Wavelet signals of gravitational waves from pulsars // Researches of the main directions of technical and physical and mathematical science: the collection of scientific works on materials II of the International scientific conference on May 10, 2014 Volgograd: "Scientific Review" publishing house, 2014. P. 16-23.

[9] P.M. Mazurkin. Geoecology: Regularities of modern natural sciences. Yoshkar-Ola: MarSTU, 2006. 336 p.

[10] P.M. Mazurkin. Identification of statistical steady regularities // Science and world: international scientific magazine. 2013. № 3(3). P. 28-33.

[11] P.M. Mazurkin. The decision 23-oh Gilbert's problems. Interdisciplinary researches in the field of mathematical modeling and informatics. Materials of the 3rd scientific and practical Internet conference. Ulyanovsk: SIMJET, 2014. P. 269-277.

[12] P.M. Mazurkin. Comparative dynamics of patenting in Russia and the USA // Intellectual property. Industrial property. 2014. No. 8. P. 52-61.

[13] P.M. Mazurkin, A.A. Vasilyev. Asymmetric signals of the electrocardiogram // Protection and protection, arrangement, indication and testing of environment. The collection of articles, under edition of professor P. M. Mazurkin. M.: Academy of Natural sciences, 2010. P. 344-348.

[14] P.M. Mazurkin, S.I. Mikhailova. Territorial ecological equilibrium $=$ Territorial ecological balance: analytical review; Russian Academy of Sciences State Public Scientific and Technical Library Institution of the Siberian office of the Russian Academy of Sciences, Mari state technical university. Novosibirsk: State Public Scientific Technical Library of the Siberian Branch of the Russian Academy of Science, 2010. 430 p. (Ecology series. Release 94).

[15] P.M. Mazurkin, A.S. Filonov. Mathematical modeling. Identification of one-factorial statistical regularities: manual. Yoshkar-Ola: MarSTU, 2006. 292 p.

[16] S.I. Mikhaylova, P.M. Mazurkin. Landscape and ecological role of an inundated meadow of the small rivers. Yoshkar-Ola: MarSTU, 2011. 154 p.

[17] The fractal analysis in fluvial geomorphology / I.K. Andronicus, A.V. Ivanov, A.A. Koronovsky, M. A. Melnik, A.V. Pozdnyakov, S. A. Chupikova, I.A. Yashkov. Under the editorship of A.V. Ivanov, A.V. Pozdnyakov. M.: University book, 2013. 188 p. 
[18] P.M. Mazurkin. Analisi dendrocronologica series. Italian Science Review. 2014; 5(14). P. 163-169. Available at URL: http://www.ias-journal.org/archive/2014/may/Mazurkin.pdf

[19] P.M. Mazurkin, “Asymmetric Wavelet Signal of Gravitational Waves." Applied Mathematics and Physics, vol. 2, no. 4 (2014): 128-134. doi: 10.12691/amp-2-4-2.

[20] P.M. Mazurkin, "Wavelet Analysis of a Number of Prime Numbers." American Journal of Numerical Analysis, vol. 2, no. 2 (2014): 29-34. doi: 10.12691/ajna-2-2-1.

[21] P.M. Mazurkin. Statistical modeling of entire prime numbers / International Journal of Engineering and Technical Research (IJETR) ISSN: 2321-0869, Volume-2, Issue-8, August 2014. P.148-158.

[22] P.M. Mazurkin. Identification of the wave patterns of behavior $/ / 14^{\text {th }}$ International multidisciplinary scientific geoconferenct \& SGEM2014. GeoConference jn NANO, BIO AND GREEN - TECHNOLOGIES FOR A SUSTAINABLE FUTURE. Conference proceedincs. Volume 1. Section Advances in Biotechnology. 17-26 June 2014. Albena, Bulgaria. P. 373-380.
[23] P.M. Mazurkin. Method of identification // 14th International multidisciplinary scientific geoconferenct \& SGEM2014. GeoConference jn NANO, BIO AND GREEN TECHNOLOGIES FOR A SUSTAINABLE FUTURE. Conference proceedincs. Volume 1. Section Advances in Biotechnology. 17-26 June 2014. Albena, Bulgaria. P. 427-434.

[24] P.M. Mazurkin. Invariants of the Hilbert Transform for 23-Hilbert Problem, Advances in Sciences and Humanities. Vol. 1, No. 1, 2015, pp. 1-12. doi: 10.11648/j.ash.20150101.11

[25] P.M. Mazurkin. Riemann's Hypothesis and Critical Line of Prime Numbers, Advances in Sciences and Humanities. Vol. 1, No. 1, 2015, pp. 13-29. doi: 10.11648/j.ash.20150101.12 